\title{
How large is the design space for stratospheric aerosol geoengineering?
}

\author{
Yan Zhang ${ }^{1}$, Douglas G. MacMartin ${ }^{1}$, Daniele Visioni ${ }^{1}$, and Ben Kravitz ${ }^{2,3}$ \\ ${ }^{1}$ Sibley School of Mechanical and Aerospace Engineering, Cornell University, Ithaca, NY, USA \\ ${ }^{2}$ Department of Earth and Atmospheric Science, Indiana University, Bloomington, IN, USA \\ ${ }^{3}$ Atmospheric Sciences and Global Change Division, Pacific Northwest National Laboratory, \\ Richland, WA, USA \\ Correspondence: Yan Zhang (yz2545@cornell.edu)
}

Received: 13 August 2021 - Discussion started: 27 August 2021

Accepted: 9 December 2021 - Published: 25 January 2022

\begin{abstract}
Stratospheric aerosol injection (SAI), as a possible supplement to emission reduction, has the potential to reduce some of the risks associated with climate change. Adding aerosols to the lower stratosphere would result in temporary global cooling. However, different choices for the aerosol injection latitude(s) and season(s) have been shown to lead to significant differences in regional surface climate, introducing a design aspect to SAI. Past research has shown that there are at least three independent degrees of freedom (DOFs) that can be used to simultaneously manage three different climate goals. Knowing how many more DOFs there are, and thus how many independent climate goals can be simultaneously managed, is essential to understanding fundamental limits of how well SAI might compensate for anthropogenic climate change, and evaluating any underlying trade-offs between different climate goals. Here, we quantify the number of meaningfully independent DOFs of the SAI design space. This number of meaningfully independent DOFs depends on both the amount of cooling and the climate variables used for quantifying the changes in surface climate. At low levels of global cooling, only a small set of injection choices yield detectably different surface climate responses. For a cooling level of $1-1.5^{\circ} \mathrm{C}$, we find that there are likely between six and eight meaningfully independent DOFs. This narrows down the range of available DOFs and also reveals new opportunities for exploring alternate SAI designs with different distributions of climate impacts.
\end{abstract}

\section{Introduction}

Reducing emissions of $\mathrm{CO}_{2}$ and other greenhouse gases (GHGs) may not be enough by itself to avoid significant risks associated with climate change. As a supplement to emission reduction, climate interventions such as stratospheric aerosol injection (SAI) may be able to temporarily reduce some of these risks. SAI involves adding aerosols or their precursors to the lower stratosphere, which would increase the stratospheric aerosol optical depth (AOD); as a result, more solar radiation would be reflected away before reaching the surface. Most climate model simulations inject $\mathrm{SO}_{2}$, which results in increased sulfate aerosols. While injecting aerosols (or a precursor gas such as $\mathrm{SO}_{2}$ ) into the stratosphere can offset the change in global mean temperature, the resulting climate would not be the same as the climate with the same temperature but without either the excess atmospheric $\mathrm{CO}_{2}$ or SAI. These residual changes depend on injection choices that could be made. As suggested in previous research, injecting aerosols at different latitudes, altitudes, and seasons would result in different spatiotemporal patterns of AOD, which in turn would lead to different regional surface climate responses (MacMartin et al., 2017; Tilmes et al., 2017, 2018a; Dai et al., 2018; Kravitz et al., 2019; Visioni et al., 2019, 2020c; Lee et al., 2020a, 2021). Understanding the global and spatiotemporal impacts of SAI and even the governance challenges requires that we not treat $\mathrm{SAI}$ as a single strategy 
but rather understand the range of outcomes across different strategies, the fundamental limits of how well SAI can compensate for GHG-driven climate change, and any underlying trade-offs among SAI strategies.

Choosing where and when to inject aerosols can be thought of as a design problem (Ban-Weiss and Caldeira, 2010; Kravitz et al., 2016; MacMartin and Kravitz, 2019); for a given choice of global cooling, the design space describes the range of all possible such injection strategies. Some strategies produce very different surface climate responses, while others can be relatively similar. Here, we only consider possible injection choices in a finite set of different latitudes and seasons. We validate in Sect. 7 that different choices for injection altitude do not produce meaningfully independent patterns of AOD. The injection longitude would not be expected to matter due to the rapid zonal mixing relative to the aerosol lifetime. Time-varying injection locations are also not considered here as their primary benefits are found over relatively short timescales compared with the aerosol lifetime in the stratosphere (Aksamit et al., 2021). The climate response to an injection strategy can be quantified by different metrics, such as surface air temperature, precipitation, and Arctic sea ice. In this study, we use surface air temperature and precipitation to quantify the climate response. We use the term "degrees of freedom" (DOFs) to describe how many independent injection choices there are in the design space and thus how many meaningfully different climate responses exist. Assuming that the climate response can reasonably be approximated as linear, the ability to independently combine $n$ patterns of climate response allows $n$ independent climate goals to be managed. Thus, the number of independent injection choices is equivalent to the number of independent climate goals that can be managed by SAI simultaneously. Most studies have only explored a single degree of freedom: injecting $\mathrm{SO}_{2}$ at one location (often the Equator) either at a fixed rate or to meet one climate objective (often global mean temperature - $T_{0}$ ) (e.g., Robock et al., 2008; Rasch et al., 2008; Kravitz et al., 2011, 2015). Kravitz et al. $(2016,2017)$ demonstrated a strategy in which three DOFs were used to manage three temperature goals: $T_{0}$, interhemispheric temperature gradient $\left(T_{1}\right)$, and Equator-to-pole temperature gradient $\left(T_{2}\right)$; the same strategy was then used in the Geoengineering Large Ensemble Project (GLENS) (Tilmes et al., 2018a). Additional studies have explored variations on these DOFs, such as Visioni et al. (2020c), who injected $\mathrm{SO}_{2}$ in only one season to meet the same set of climate goals, or Lee et al. (2020a), who used the same set of DOFs as in Tilmes et al. (2018a) to meet different sets of climate goals, including $T_{0}$, the latitude of the Intertropical Convergence Zone (ITCZ), the amount of Arctic September sea ice (SSI), and global mean precipitation $\left(P_{0}\right)$. Higher-latitude injections in different seasons have been shown to have different efficacies in preserving SSI; e.g., spring-only injection at $60^{\circ} \mathrm{N}$ restores twice the amount of SSI compared to annually constant injection at that latitude (Lee et al., 2021).
A key open question from these design studies is how many other strategies are unexplored (e.g., MacMartin and Kravitz, 2019); in other words, how many independent degrees of freedom are there?

In this study, we estimate the number of DOFs of the design space for SAI. Knowing how many DOFs there are in the design space quantifies the number of independent climate goals that can be managed simultaneously by a SAI strategy. In order to be managed simultaneously, those independent climate goals cannot conflict. (For example, $T_{0}$ and $P_{0}$ are conflicting and cannot be managed simultaneously; see, e.g., Bala et al., 2008; Tilmes et al., 2013; Lee et al., 2020a.) Knowing the number of DOFs also helps understand the full range of possible climate outcomes and what climate outcomes cannot be achieved by SAI strategies. In this study, we focus only on $\mathrm{SO}_{2}$ injections and evaluate the range only in one model. However, the results will depend primarily on the constraints imposed by stratospheric circulation and the lifetime of the aerosols in the stratosphere (Tilmes et al., 2017; MacMartin et al., 2017; Dai et al., 2018); as such, many of the conclusions can be expected to be applicable regardless of aerosol choice.

The aerosols will primarily stay in the same hemisphere where they are injected and be transported mostly poleward by the stratospheric Brewer-Dobson circulation (Tilmes et al., 2017; MacMartin et al., 2017). Thus, injecting in one hemisphere preferentially increases AOD in that hemisphere; injecting further poleward increases the AOD burden further poleward. Injecting above the Equator produces an AOD peak in the tropics (Kravitz et al., 2019). More generally, different choices of injection latitude, altitude, and season lead to different spatiotemporal AOD patterns as a result of the seasonally varying stratospheric circulation. However, not all choices contribute the same level of "uniqueness" (MacMartin et al., 2017; Visioni et al., 2019, 2020c). For example, injecting at the Equator would produce very different patterns of AOD compared to injecting at $30^{\circ} \mathrm{N}$, but the patterns of AOD produced by injecting at $31^{\circ} \mathrm{N}$ should not be expected to be very different from injecting at $30^{\circ} \mathrm{N}$. As more choices of injection latitude are considered, there exists a diminishing return on the "uniqueness" contributed by additional choices of injection latitude. That leads to the question of how many meaningfully independent patterns of AOD are possible given the constraints imposed by stratospheric circulation.

There are two distinct steps in the analysis herein. The first step is to consider how different the spatiotemporal AOD patterns are for different injection choices. And second, to know whether the AOD patterns from two different injection choices are sufficiently similar to treat them as effectively equivalent, or sufficiently distinct to treat them as two separate DOFs, one needs to relate how similar or dissimilar the patterns of AOD are to how similar or dissimilar the resulting climate responses are. Identifying the number of DOFs only needs to consider injections that produce meaningfully 
different climates; herein, we define "meaningfully different" based on the ability to detect the difference in climate after 20 years, given natural variability - and this threshold clearly depends on the choice of climate variables to be considered and the amount of cooling desired. For example, injecting aerosols at $30^{\circ} \mathrm{N}$ only in the summer or only in the fall would yield different patterns of AOD. The difference in resulting climate could be distinguishable against the background climate variability if the desired amount of cooling is high. However, by reducing the level of cooling, the difference would become indistinguishable.

The next section describes the climate model and simulations used. Section 3 assesses the differences in spatiotemporal AOD patterns from 29 different injection choices, sampling different latitudes and seasons of injection, and quantifies the size of design spaces with different numbers of DOFs using a metric based on the angle between different patterns of AOD. Section 4 identifies a relationship between how similar or dissimilar AOD patterns are and how similar or dissimilar the corresponding climate responses are, using existing simulations that were conducted with various different choices for climate goals and/or different DOFs. Section 5 then quantifies how large the difference in surface climates needs to be in order to be meaningfully different at different levels of cooling. Finally, we combine these pieces of analysis in Sect. 6 to show that for a cooling level of $1-1.5^{\circ} \mathrm{C}$, for example, there are between 6 and 8 DOFs.

\section{Model and simulations}

All simulations in this study were conducted using the Community Earth System Model version 1 with the Whole Atmosphere Community Climate Model as the atmospheric component, CESM1(WACCM). CESM1(WACCM) is a fully coupled Earth system model which includes atmosphere, ocean, land, and sea ice components (Mills et al., 2017). The model has a horizontal resolution of $0.95^{\circ}$ latitude by $1.25^{\circ}$ longitude, with 70 vertical levels that extend from the Earth's surface to $140 \mathrm{~km}$ in altitude, and stratospheric aerosols have been shown to reasonably match observations after the Mt. Pinatubo eruption (Mills et al., 2017). With the exception of a few cases noted below, we use existing output from previous simulations for our analysis.

To assess the range of possible spatiotemporal patterns of AOD arising from different injection choices, we sample 29 possible choices in the AOD design space, including injections at low and middle latitudes as described by Visioni et al. (2019), and high-latitude injections as described by Lee et al. (2021); the set of 29 possible choices is illustrated in Fig. 1. Visioni et al. (2019) include injections at five different latitudes: $30,15^{\circ} \mathrm{N}$, Equator, 15, and $30^{\circ} \mathrm{S}$, as in Tilmes et al. (2017). For each latitude, injections are simulated both annually constant and restricted to each season: December-January-February (DJF), March-April-

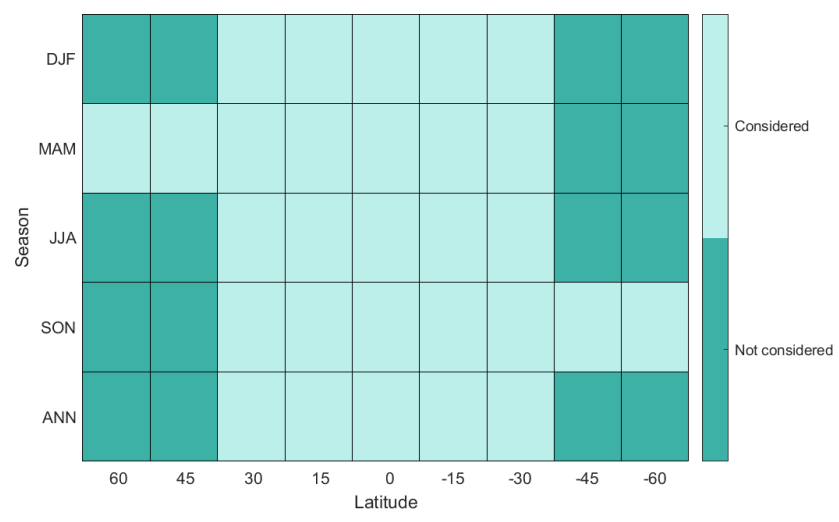

Figure 1. The 29 injection choices that we considered in our analysis for AOD patterns are shown in light green. The vertical axis shows the injection season of each injection choice, either injecting in only one season (DJF, MAM, JJA, or SON) or constantly throughout the year (ANN). The horizontal axis shows the injection latitude: from left to right, they are $60,45,30,15^{\circ} \mathrm{N}$, Equator, 15 , 30,45 , and $60^{\circ} \mathrm{S}$.

May (MAM), June-July-August (JJA), and SeptemberOctober-November (SON). In each simulation, $6 \mathrm{Tg} \mathrm{yr}^{-1}$ of $\mathrm{SO}_{2}$ are injected into the lower stratosphere, approximately 6-7 $\mathrm{km}$ above the tropopause at $180^{\circ} \mathrm{E}$ (about $25 \mathrm{~km}$ for Equator and $15^{\circ} \mathrm{N} / \mathrm{S}, 23 \mathrm{~km}$ for $30^{\circ} \mathrm{N} / \mathrm{S}, 16 \mathrm{~km}$ for $45^{\circ} \mathrm{N} / \mathrm{S}$, and $15 \mathrm{~km}$ for $60^{\circ} \mathrm{N} / \mathrm{S}$ ). Simulations were conducted for 5 years (2040-2044), which is sufficient for estimating the steady-state AOD pattern (Visioni et al., 2019), though of course not for estimating the climate response to this forcing. The high-latitude injections included here are not exactly the same as those described in Lee et al. (2021), which have a higher injection rate of $12 \mathrm{Tg} \mathrm{yr}^{-1}$ and only consider injecting at $60^{\circ} \mathrm{N}$ and further poleward. To be consistent with simulations performed by Visioni et al. (2019), we conducted additional simulations of spring (MAM or SON) injection at $45^{\circ} \mathrm{N}, 45^{\circ} \mathrm{S}, 60^{\circ} \mathrm{N}$, and $60^{\circ} \mathrm{S}$ for 5 years from 2040 to 2044 with an injection rate of $6 \mathrm{Tg} \mathrm{yr}^{-1}$ to complete the sample set. Following Lee et al. (2021), the other seasons of injection at high latitudes are not expected to be particularly effective. In addition, Lee et al. (2021) have pointed out that the spatiotemporal distribution of AOD arising from injection at $75^{\circ} \mathrm{N}$ is similar to that arising from injection at $60^{\circ} \mathrm{N}$, and injecting at latitudes north of $75^{\circ} \mathrm{N}$ provides diminishing returns in terms of albedo enhancement; thus, injections at latitudes higher than $60^{\circ} \mathrm{N} / \mathrm{S}$ are not included in this sample set. Figure 2 shows the spatiotemporal patterns of AOD in each of these four spring injections at high latitudes (see Visioni et al., 2019, for the remaining cases). This gives us a total of 29 different injection cases and associated spatiotemporal patterns of AOD. In Sect. 3, we rank the 29 injection cases based on the uniqueness of their AOD patterns, which are then used to identify the number of meaningfully independent injection choices. In Sect. 7, we show that the 
Table 1. Injection design of the five existing SAI simulations analyzed in this study.

\begin{tabular}{|c|c|c|c|c|c|}
\hline $\begin{array}{l}\text { Name of } \\
\text { simulation }\end{array}$ & $\begin{array}{l}\text { Injection } \\
\text { latitude }\end{array}$ & Injection season & $\begin{array}{r}\text { Number of } \\
\text { ensemble } \\
\text { members }\end{array}$ & Objectives & Reference \\
\hline GLENS & $\begin{array}{l}30,15^{\circ} \mathrm{N} \\
15,30^{\circ} \mathrm{S}\end{array}$ & annually constant & 21 & $T_{0}, T_{1}, T_{2}$ & Tilmes et al. (2018a) \\
\hline iSpring & $\begin{array}{l}30,15^{\circ} \mathrm{N} \\
15,30^{\circ} \mathrm{S}\end{array}$ & $\begin{array}{l}\text { MAM at } 30 \text { and } 15^{\circ} \mathrm{N} \text {; } \\
\text { SON at } 15 \text { and } 30^{\circ} \mathrm{S}\end{array}$ & 3 & $T_{0}, T_{1}, T_{2}$ & Visioni et al. (2020c) \\
\hline iAutumn & $\begin{array}{l}30,15^{\circ} \mathrm{N} \\
15,30^{\circ} \mathrm{S}\end{array}$ & $\begin{array}{l}\mathrm{SON} \text { at } 30 \text { and } 15^{\circ} \mathrm{N} ; \\
\mathrm{MAM} \text { at } 15 \text { and } 30^{\circ} \mathrm{S}\end{array}$ & 3 & $T_{0}, T_{1}, T_{2}$ & Visioni et al. (2020c) \\
\hline $\begin{array}{l}\text { Equatorial } \\
\text { (EQ) }\end{array}$ & Equator & annually constant & 3 & $T_{0}$ & Kravitz et al. (2019) \\
\hline $\begin{array}{l}\text { PREC (first } \\
\text { simulation } \\
\text { in Lee et al., 2020a) }\end{array}$ & $\begin{array}{l}30,15^{\circ} \mathrm{N} \\
15,30^{\circ} \mathrm{S}\end{array}$ & annually constant & 1 & $\begin{array}{l}T_{0}, \text { ITCZ, } \\
\text { SSI }\end{array}$ & Lee et al. (2020a) \\
\hline
\end{tabular}

(a)

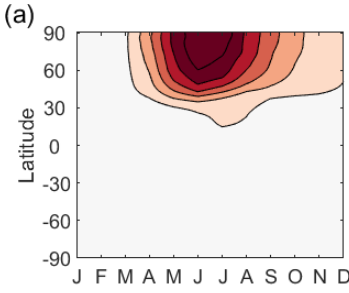

(c)

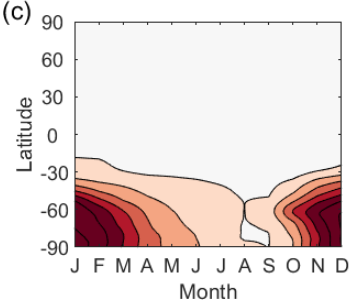

(b)

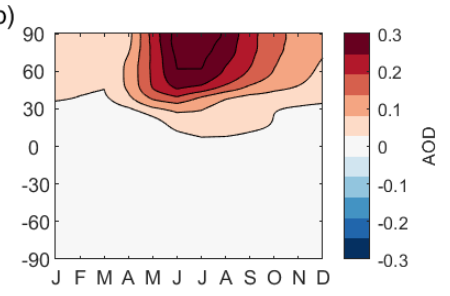

(d)

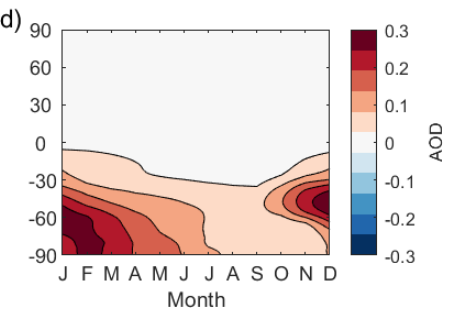

Figure 2. Spatiotemporal AOD patterns of spring injections at (a) $60^{\circ} \mathrm{N}$, (b) $45^{\circ} \mathrm{N}$, (c) $60^{\circ} \mathrm{S}$, and (d) $45^{\circ} \mathrm{S}$. The AOD patterns of spring injections in the same hemisphere are similar to each other, while the injections in the opposite hemispheres produce very different AOD patterns.

uniqueness of stratospheric AOD patterns does not depend on the altitude of injection, using simulation data from Tilmes et al. (2017) that include $\mathrm{SO}_{2}$ injection either $1 \mathrm{~km}$ above the tropopause or 6-7 km above the tropopause.

In addition to these shorter simulations that we use to assess the range of possible spatiotemporal AOD patterns from different injection choices, five sets of solar geoengineering simulations from existing studies (Tilmes et al., 2018a; Kravitz et al., 2019; Visioni et al., 2020c; Lee et al., 2020a) are used to analyze the connection between the patterns of stratospheric AOD and surface climate responses (see Table 1). These five sets were all performed in CESM1(WACCM), with Representative Concentration Path-

way 8.5 (RCP8.5) as the background emissions scenario, and used a feedback algorithm (Kravitz et al., 2017) to adjust $\mathrm{SO}_{2}$ injection rates to maintain one or more climate objectives. Each simulation takes the 20-year average of annual-mean temperature from 2010-2029 in the RCP8.5 emissions scenario as the target value for $T_{0}$. Maintaining $T_{0}$ constant at the 2010-2029 average results in $4{ }^{\circ} \mathrm{C}$ of global mean cooling in each of these simulations by 2070-2089. The equatorial case adjusts the single $\mathrm{SO}_{2}$ injection rate to meet $T_{0}$. The other simulations adjust $\mathrm{SO}_{2}$ injection rates at multiple latitudes to simultaneously meet $T_{0}$ and additional climate objectives (see Table 1); these additional objectives include $T_{1}$, $T_{2}$, ITCZ (using the centroid of precipitation between $20^{\circ} \mathrm{S}$ and $20^{\circ} \mathrm{N}$ as a proxy), and SSI. Table 1 lists the injection seasons and latitudes, the number of ensemble members, and the design objectives of the five sets of simulations.

\section{Diminishing returns on the number of degrees of freedom}

In this section, we consider 29 different injection choices, sampling from different latitudes and seasons of injection, as well as three additional cases that we use to verify that the set of 29 is sufficiently complete. The AOD pattern from a given injection choice (a given latitude and season of injection) is largely determined by the stratospheric circulation and aerosol lifetime, which constrains what spatiotemporal patterns are achievable (Tilmes et al., 2017; MacMartin et al., 2017). The AOD pattern resulting from any particular choice of latitude and season can be approximated by a linear combination of other choices. Our goal in this paper is to determine how many distinct injection choices are needed to adequately approximate all of the possible AOD patterns. What constitutes "adequacy" is determined in subsequent sections. 
To describe any pattern of AOD, we consider the zonalmean pattern as a function of both latitude and time of year. In order to treat these two dimensions consistently and yield AOD patterns independent of our sampling resolution in each dimension, we weight the monthly mean zonal mean AOD at each latitude and month by the corresponding incoming solar energy (petajoules) at the top of the atmosphere (TOA). We then represent the weighted spatiotemporal AOD pattern from each injection choice as a vector $\boldsymbol{a}, \boldsymbol{a}=\left[a_{1}, a_{2}, \ldots, a_{\ell}\right]$, the length of which is $\ell=\ell_{\text {lat }} \times \ell_{\text {month }}$, where $\ell_{\text {lat }}=192$ (the resolution of the model we used), and $\ell_{\text {month }}=12$. One way of quantifying how similar or dissimilar two patterns of AOD are is to consider the angle $\theta_{\mathrm{AOD}}=\angle\left(\boldsymbol{a}_{i}, \boldsymbol{a}_{j}\right)$ between their vector representations $\boldsymbol{a}_{i}$ and $\boldsymbol{a}_{j}$. This implicitly assumes that the patterns of AOD are sufficiently linear for $1-4{ }^{\circ} \mathrm{C}$ of cooling, although nonlinearities will become increasingly important at higher forcing levels (MacMartin et al., 2017; Visioni et al., 2020b). Thus, the angle between two vectors $\boldsymbol{a}_{i}$ and $\boldsymbol{a}_{j}$ that represent the AOD patterns of the same injection choice with different injection rates is negligible, while only the magnitudes of those vectors are different. Two AOD patterns that are different only in magnitude can thus be matched by adjusting injection rates, and thus are not considered as meaningfully different. Therefore, the angle between two vectors $\boldsymbol{a}_{i}$ and $\boldsymbol{a}_{j}$ describes how meaningfully different these two AOD patterns are. We can illustrate this using the AOD patterns shown in Fig. 2. The AOD patterns of injection at $60^{\circ} \mathrm{N}$ and $60^{\circ} \mathrm{S}$ are very dissimilar; the angle between the vector representations of these two AOD patterns is $84^{\circ}$. By contrast, the AOD patterns of injection at 60 and $45^{\circ} \mathrm{N}$ are similar; the angle between these two AOD patterns is only $12^{\circ}$.

With the vector representation explained above, our goal is to select a subset from the set of 29 injection choices such that any possible AOD pattern can be adequately represented by a linear combination of injection choices from this subset. Any given subset of linearly independent injection choices does not produce an orthogonal set but could be orthogonalized if needed. Determining the dimension of the set necessary to meet this goal is equivalent to determining the number of DOFs of SAI.

First, we need to verify that our set of 29 injection choices sufficiently describes all of the possible AOD patterns of other injection choices that we have not simulated. To do so, we choose three additional verification cases, which are annual injections at $7.5,22.5$, and $37.5^{\circ} \mathrm{N}$, and quantify how well each of these can be represented by a linear combination of the 29 injection choices.

Mathematically, the linear combination that is most similar to the simulated pattern of AOD is the projection of its vector representation onto the space formed by the 29 injection choices. Solving the best approximation of the pattern of AOD can be formed as a constrained linear least-square problem of finding the projection onto the set of 29 injection choices: $\operatorname{argmin}_{\hat{\boldsymbol{x}}}\|\hat{\boldsymbol{d}}(\hat{\boldsymbol{x}})-\boldsymbol{d}\|$

$\operatorname{sbj}$ to $\hat{\boldsymbol{d}}(\hat{\boldsymbol{x}})=\mathbf{Q}_{29} \hat{\boldsymbol{x}}$

$\hat{x}_{i} \geq 0, i=1, \ldots, 29$,

where $\boldsymbol{d}$ is the vector representation of the AOD pattern of each verification case, which is obtained from CESM1(WACCM) simulation, $\hat{d}$ is the best approximation of $\boldsymbol{d}, \mathbf{Q}_{29}$ is the set of vector representations of the AOD patterns of the 29 injection choices, and $\hat{\boldsymbol{x}}$ is the vector of best-approximating linear coefficients. All linear coefficients $\hat{x}_{i}$ are constrained to be non-negative numbers, as injection rates cannot be negative.

By calculating the angle between the vector representation of the simulated AOD pattern and the vector representation of the approximated AOD pattern, we can assess how similar the simulated and approximated AOD patterns are. For annually constant injections at $7.5,22.5$, and $37.5^{\circ} \mathrm{N}$, the angles between simulated and approximated AOD patterns are 7.6, 5.9 , and $6.1^{\circ}$, respectively. The AOD from injection at $7.5^{\circ} \mathrm{N}$ is roughly a linear combination of injections at the Equator and $15^{\circ} \mathrm{N}$, with a little over half of $\mathrm{SO}_{2}$ injected at $15^{\circ} \mathrm{N}$. Similarly, the AOD from injection at $22.5^{\circ} \mathrm{N}$ is roughly a linear combination of injections at 15 and $30^{\circ} \mathrm{N}$, and the AOD from injection at $37.5^{\circ} \mathrm{N}$ is roughly a linear combination of injections at 30 and $45^{\circ} \mathrm{N}$. The simulated and approximated spatiotemporal AOD patterns of these three verification cases are shown in Fig. 3. Although we do not verify the AOD patterns for an injection on the Southern Hemisphere, we expect to see a similar linear combination of injections in the same hemisphere at some latitudes lower and higher than its injecting latitude. Based on this comparison, the approximated AOD patterns are adequately similar to the simulated AOD patterns, as long as the threshold for an "adequate" approximation of the AOD is larger than $7.6^{\circ}$ (which it will be here, as shown in subsequent sections). Allowing this small difference between the approximated and simulated AOD patterns, the set of 29 injection choices thus adequately describes other possible AOD patterns that we have not simulated.

With the set of 29 choices of injection locations and times, we can evaluate a wide range of possible selections of injection choices. Sets with different numbers of injection choices as well as different selections of the same number of injection choices will do a better or worse job at spanning the space of possible AOD patterns. One way to quantify how well the overall space of possible AOD patterns can be approximated by a particular subset of $n$ injection choices is to compute the maximum angle, $\theta_{\max }$, that can be formed between the subset of $n$ choices and any other injection choices that are not selected. That is, how well can the AOD pattern from any other choice be represented by a linear combination of the $n$ elements in the subset? The smaller $\theta_{\max }$ is, the better the AOD pattern from any other possible injection choice can be equivalently obtained by only choosing injections from the subset 
(a)

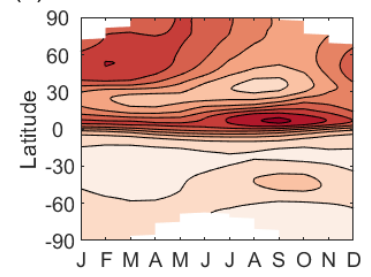

(d)

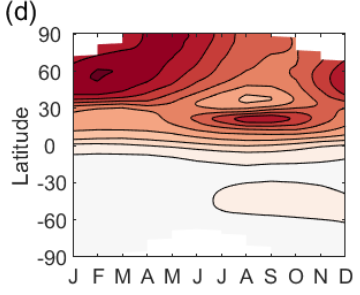

(g)

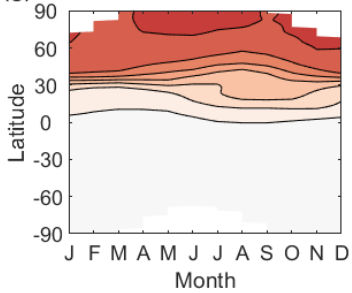

(b)

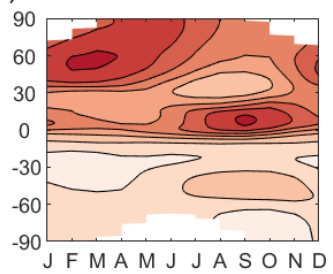

(e)

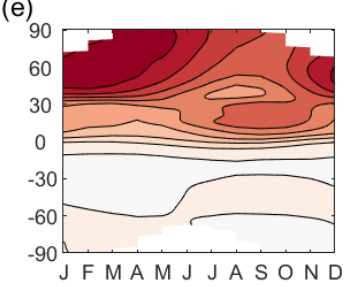

(h)

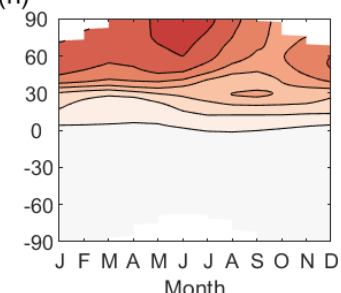

(c)

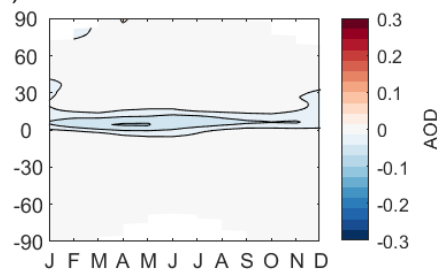

(f)

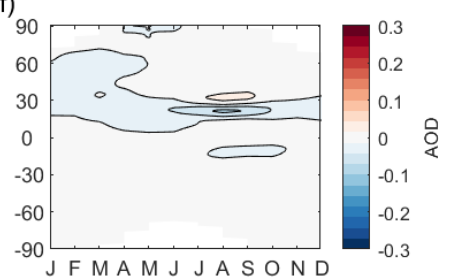

(i)

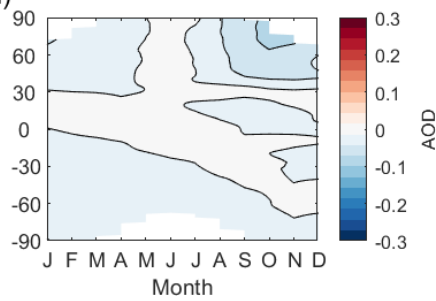

Figure 3. Comparison of simulated AOD patterns and the best approximation to these AOD patterns obtained from a linear combination of other injection choices within the set of 29 cases considered here. From top to bottom are the spatiotemporal AOD patterns for injections at $7.5,22.5$, and $37.5^{\circ} \mathrm{N}$, respectively. In each horizontal panel, plots from left to right are the AOD pattern obtained from CESM1(WACCM) simulations, the AOD pattern approximated using the set of 29 injection choices, and the difference between these two patterns. The angles between the simulated AOD pattern and the AOD pattern approximated using the set of 29 injection choices are $7.6,5.9$, and $6.1^{\circ}$, respectively.

of selected injection choices. This provides a way to quantify how well the overall space is approximated by a particular subset of $n$ injection choices. By optimizing over $\theta_{\max }$, we can determine both what the "best" subset is of any given dimension (number of DOFs or injection choices), and equally important, how much error there would be in trying to capture any achievable AOD pattern with only a relatively few different injection choices.

In choosing subsets, we enforce hemispheric symmetry such that if an injection choice in one hemisphere is included, then the corresponding choice in the opposite hemisphere is also included (e.g., MAM in the Northern Hemisphere and SON in the Southern Hemisphere). While the seasonal circulation patterns are not exactly symmetric between the hemispheres, they are sufficiently similar that this is a reasonable simplification that reduces the number of sets to search over. For injections at the Equator, we similarly either include or do not include opposite seasons (e.g., DJF and JJA, or MAM and SON). With hemispheric symmetry, the only way to have a set with an odd number of DOFs is to include annually constant equatorial injection; we revisit this case in the discussion.

Mathematically, the steps above can be described as follows. First, for each subset $\mathbf{Q}_{j}$ of $n$ injection choices, we identify the maximum angle that can be formed between that subset and any other injection choices in the set of 29 that are not selected:

$\theta_{\max }\left(\mathbf{Q}_{j}\right)=\max _{1 \leq i \leq k} \angle\left(\boldsymbol{a}_{i}, \mathbf{Q}_{j}\right), \boldsymbol{a}_{i} \in\left[\mathbf{Q}_{29} \backslash \mathbf{Q}_{j}\right]$,

where $k=29-n$, the total number of injection choices that are not selected by the set $\mathbf{Q}_{j}$.

Taking $n=4$ as an example, we can identify all possible combinations of four injection choices from the set of 29 . With the enforced constraint of hemispheric symmetry, there are a total of 91 different combinations. For each of these possible combinations, we calculate the angle formed between each of the unselected injection choices and the selected set of four and find the maximum angle. For illustration, Fig. 4 shows an example (sub-optimal) set of four injection choices: summer injection at $30,15^{\circ} \mathrm{N}, 15$, and $30^{\circ} \mathrm{S}$, and lists the angles formed between each of the unselected injection choices and the example set of four.

Among all possible subsets of $n$ injection choices $\left(\mathbf{Q}_{j} \in\right.$ Q), we identify which subset has the smallest maximum angle and denote the "best" subset that minimizes $\theta_{\max }$ as $\mathbf{Q}^{*}(n)$ :

$$
\mathbf{Q}^{*}(n)=\operatorname{argmin}_{Q_{j} \in Q} \theta_{\max }\left(\mathbf{Q}_{j}\right) .
$$




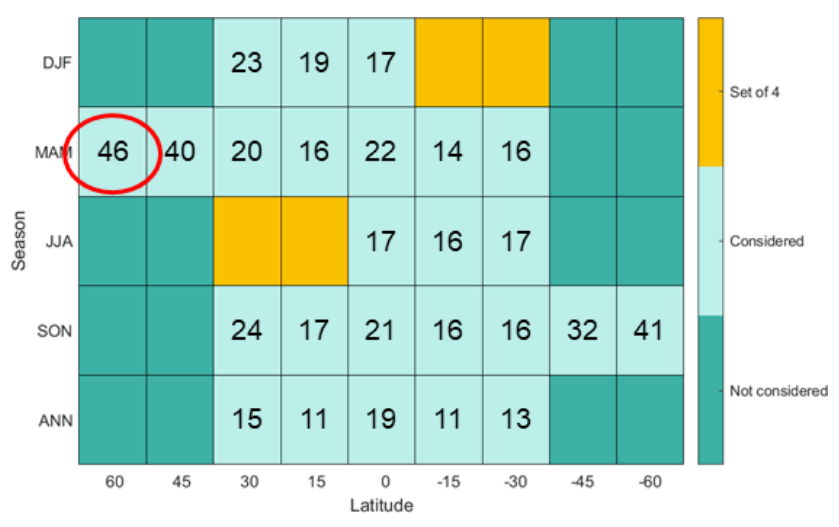

Figure 4. Angles (in degrees) between each unselected injection choice and a set of four injection choices (in orange): summer injection at $30,15^{\circ} \mathrm{N}, 15$, and $30^{\circ} \mathrm{S}$. The $x$ axis is the injection latitude and the $y$ axis is the injection season. The maximum angle is $46^{\circ}$ (highlighted by a red circle), formed between spring injection at $60^{\circ} \mathrm{N}$ and this set of four.

$\mathbf{Q}^{*}(n)$ is the subset of size $n$ that best approximates any achievable pattern of AOD. The angle $\theta_{\max }$ of the "best" set of $n$ is denoted as $\theta^{*}(n)$.

Still using $n=4$ as an example, we calculate the maximum angle for all possible combinations of four injection choices. The set of spring injections at $45^{\circ} \mathrm{N}$ and $45^{\circ} \mathrm{S}$ and autumn injections at $15^{\circ} \mathrm{N}$ and $15^{\circ} \mathrm{S}$ has the smallest maximum angle, which is $26^{\circ}$ (Fig. 5).

For each possible value of $n$, we find the "best" set and corresponding angle $\theta^{*}(n)$, plotted in Fig. 6 . Strictly speaking, because we only sampled 29 possible injection choices (out of an infinite theoretical space), $\theta^{*}(n)$ is simply our best estimate for the maximum angle between a subspace of $n$ DOFs and any possible AOD pattern of injection choices that does not fall into this subspace.

\section{Comparing AOD and surface climate}

Figure 6 shows that there are diminishing marginal returns for how many degrees of freedom are included. However, the analysis in Sect. 3 does not indicate what degree of approximation is sufficient. The next step in our analysis is to evaluate the relationship between how similar or dissimilar two AOD patterns are, and how similar or dissimilar the corresponding surface climate responses are. This relationship is crucial for determining a threshold for whether two patterns of AOD from different injection choices are sufficiently different to count as two independent degrees of freedom, or sufficiently similar to be effectively the same choice.

To estimate this relationship, we consider the different strategies described in Table 1. Each of these uses either different injection choices or has different climate goals, leading to different patterns of AOD and corresponding different surface climate responses. By comparing the difference in
AOD patterns and surface climate responses, we can derive a function that describes how the similarity in surface climate responses relates to the similarity in the AOD patterns that they arise from.

The AOD pattern and corresponding surface climate responses are obtained by averaging over all available ensemble members for each strategy in Table 1 and taking the difference between the 2070-2089 average and the 2010 2029 average in the RCP8.5 emissions scenario. As explained in Sect. 3, the monthly mean zonal-mean AOD is weighted by the TOA incoming solar energy as a function of latitude and time of year. For the climate response, this establishes the changes from a climate with neither SAI nor increased greenhouse gases to a climate with both. To evaluate how the surface climate varies for different strategies, herein we only consider annual-mean surface air temperature and precipitation; this assumes that if these two variables are similar, then changes in other surface climate variables, such as precipitation minus evaporation $(P-E)$, will also be sufficiently similar, and also ignores shifts in the seasonal cycle (Jiang et al., 2019) as these tend to be smaller than the annual-mean changes.

To estimate how large a change in the spatiotemporal pattern of AOD is needed to obtain a detectably different pattern of surface climate response, we consider detectability over a 20 -year period. Therefore, we normalize the surface temperature and precipitation changes by the variability in 20-year averages, calculated from the across-ensemble variability from 2010-2029 in the RCP8.5 emissions scenario, where 21 ensemble members are available. If the variability were uncorrelated from year to year, this value would simply be a factor of $\sqrt{20}$ smaller than the interannual variability; this would be a reasonable approximation for precipitation but not for temperature. Normalizing by variability also allows temperature and precipitation changes to be compared in consistent units (Ricke et al., 2010).

To analyze the differences in AOD and surface climate for different strategies, we define the AOD space, temperature space, and precipitation space. In Sect. 3, we define the vector representation of AOD patterns as $\boldsymbol{a} . \boldsymbol{a}$ represents an achievable spatiotemporal AOD pattern produced by a possible injection choice. The AOD space $\mathcal{A}$ is a $\ell$-dimensional space, $\mathcal{A} \subset \mathbb{R}^{\ell}$, that includes all possible values of $\boldsymbol{a}$. Similarly, the temperature space $\mathcal{T}$ and the precipitation space $\mathcal{P}$ are both $m$-dimensional spaces, $\mathcal{T} \subset \mathbb{R}^{m}$ and $\mathcal{P} \subset \mathbb{R}^{m}$, where $m$ is equal to the number of latitudes multiplied by the number of longitudes, $m=m_{\text {lat }} \times m_{\text {lon }}$, where $m_{\text {lat }}=192$, and $m_{\text {lon }}=288$ (the resolution of the model we used). Any vector $\boldsymbol{T}$ in $\mathcal{T}$ represents a possible surface air temperature response to a possible injection choice, and any vector $\boldsymbol{P}$ in $\mathcal{P}$ represents a possible precipitation response to a possible injection choice:

$\boldsymbol{T}=\left[T_{1}, T_{2}, \ldots, T_{m}\right]^{T}, \boldsymbol{T} \in \mathcal{T}$ 


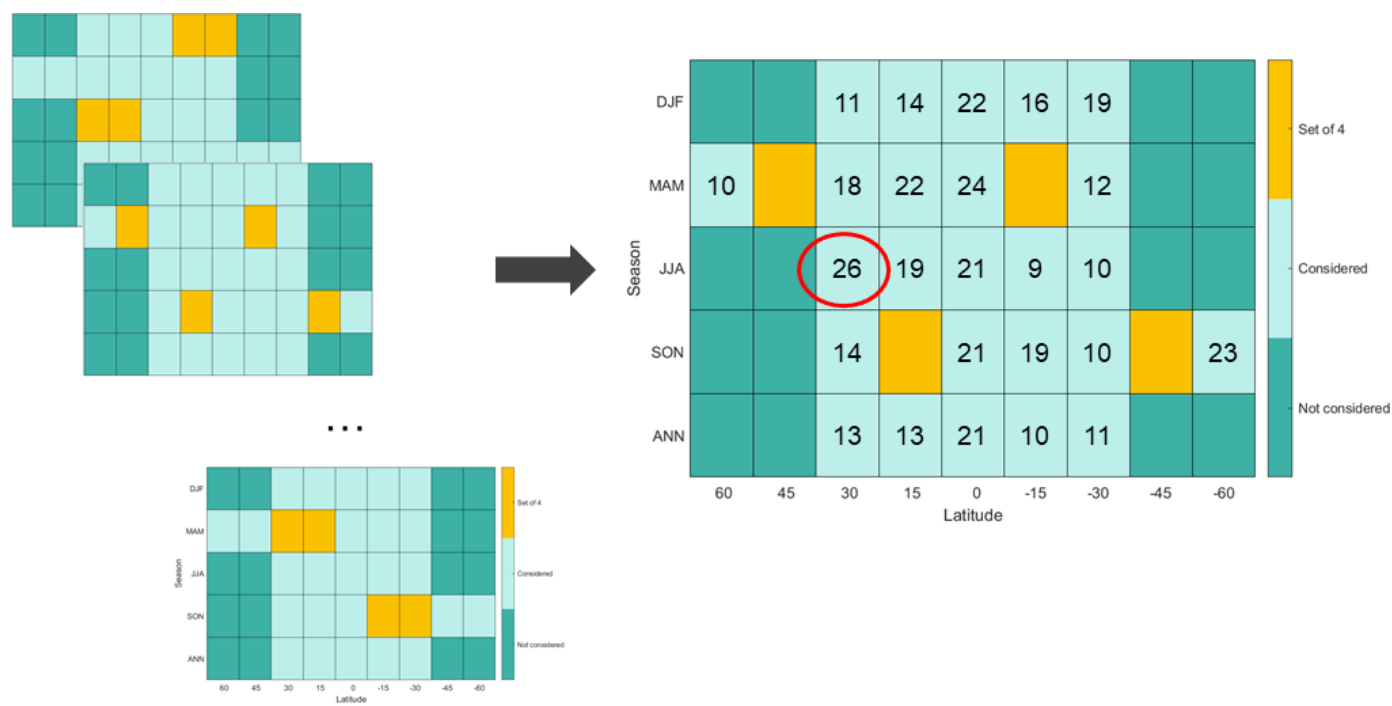

Figure 5. A schematic diagram showing how to find the smallest maximum angle $\theta^{*}(4)$ for a set of four injection choices. We first look through all possible combinations of four injection choices and calculate the maximum angle $\theta_{\max }$, and then identify which set has the smallest value of $\theta_{\max }$. The "best" set of four includes spring injections at $45^{\circ} \mathrm{N}$ and $45^{\circ} \mathrm{S}$ and autumn injections at $15^{\circ} \mathrm{N}$ and $15^{\circ} \mathrm{S}$. The maximum angle for this "best" set of 4 is $26^{\circ}$ (highlighted by a red circle), formed between this set and summer injection at $30^{\circ} \mathrm{N}$; this is much smaller than $46^{\circ}$, the maximum angle found in the example in Fig. 4.

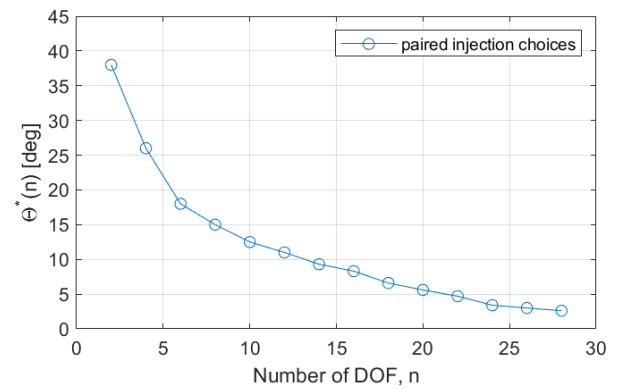

Figure 6. The maximum angle $\theta^{*}(n)$ formed between a subspace of $n$ DOFs and any other injection choices outside this subspace decreases as the number of DOFs increases.

$\boldsymbol{P}=\left[P_{1}, P_{2}, \ldots, P_{m}\right]^{T}, \boldsymbol{P} \in \mathcal{P}$,

where $T_{1}, \ldots, T_{m}$ are temperature responses, and $P_{1}, \ldots, P_{m}$ are precipitation responses, both in dimensionless units of standard deviations.

In the AOD space, temperature space, and precipitation space defined above, we evaluate the differences between each possible pair of the five SAI strategies described in Table 1, i.e., 10 pairwise comparisons. As in Sect. 3, the difference between AOD patterns for different pairs of strategies is evaluated by computing the angle between them, $\theta_{\mathrm{AOD}}$. For temperature and precipitation, the difference between two strategies is evaluated by computing the temperature distance, $d_{t}$, or the precipitation distance, $d_{\mathrm{p}}$. The temperature distance is defined as the area-weighted $L^{2}$ norm (root mean square; rms) of the difference between the two vec- tor representations of surface air temperature responses, to count all areas on the Earth equally. Similarly, the precipitation distance is defined as the area-weighted $L^{2}$ norm (rms) of the difference between the two vector representations of precipitation responses. Among the 10 pairwise comparisons, GLENS and EQ have the largest temperature distance, though it is still an order of magnitude smaller than the temperature distance between GLENS and the projected 20-year average (2070-2089) climate response under RCP8.5 (Fig. 7a and b). The precipitation distance between GLENS and EQ is also smaller than that between GLENS and RCP8.5 (Fig. 7c and d). Among all 10 pairwise comparisons, the temperature distances are always larger than the corresponding precipitation distance. That is, the changes in temperature, compared to variability, are larger than the changes in precipitation. To conclude, a small angle between the vector representations of AOD patterns indicates the two compared SAI strategies yield similar AOD patterns, and a small value of $d_{t}$ or $d_{\mathrm{p}}$ indicates that the two compared SAI strategies have similar surface air temperature responses or precipitation responses. Likewise, a larger AOD angle, temperature distance, or precipitation distance implies less similar AOD patterns, surface air temperature, or precipitation.

To estimate the relationships between $\theta_{\mathrm{AOD}}$ and $d_{t}$ and between $\theta_{\mathrm{AOD}}$ and $d_{\mathrm{p}}$, we perform linear regressions on the data points obtained from the 10 pairwise comparisons among the five different SAI strategies in Table 1 (Fig. 8). We constrain the linear regressions to go through zero because an identical AOD pattern should yield an identical temperature and precipitation response. The linear functions are obtained as

$\theta_{\mathrm{AOD}}=6.1 d_{t}$ 
(a)

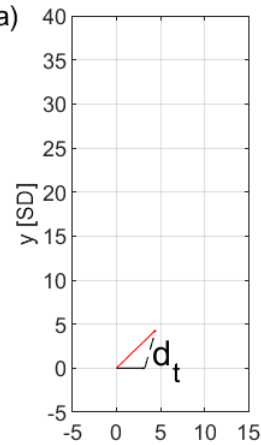

(c)

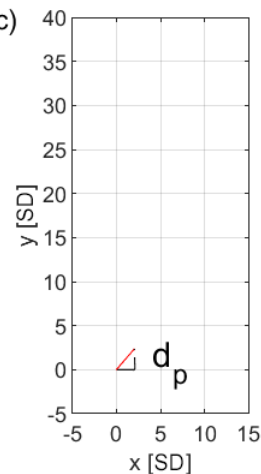

(b)

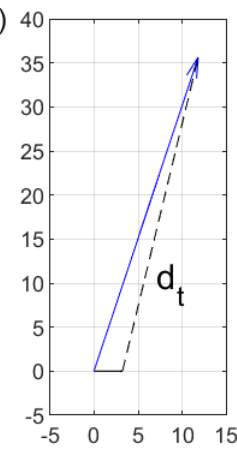

(d)

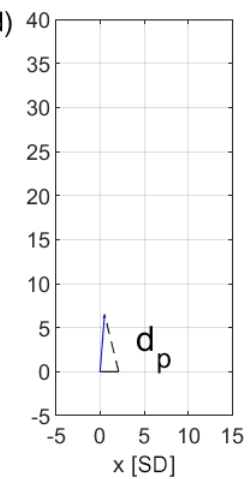

Figure 7. (a) The temperature distance between GLENS (black) and EQ (red), (b) the temperature distance between GLENS (black) and RCP8.5 (blue), (c) the precipitation distance between GLENS (black) and EQ (red), and (d) the precipitation distance between GLENS (black) and RCP8.5 (blue), shown on the 2-D plane that contains both area-weighted vectors (while both vectors are $m$ dimensional, there is a unique plane that contains both). Both temperature and precipitation are expressed in the number of standard deviations (and are thus dimensionless). In each plot, both the $x$ and $y$ axes are distances in the number of standard deviations. In panels (a) and (b), SD is the standard deviation of 20-year averages of temperature, calculated from the across-ensemble variability from 2010-2029 in RCP8.5 simulations. In panels (c) and (d), $\mathrm{SD}$ is the standard deviation of 20-year averages of precipitation.

$\theta_{\mathrm{AOD}}=9.9 d_{\mathrm{p}}$.

As shown in Fig. 8, pairs of strategies with relatively similar AOD patterns have relatively similar temperature and precipitation responses, and conversely, pairs of strategies with very different $A O D$ patterns result in very different temperature and precipitation responses. However, the relationships between $\theta_{\mathrm{AOD}}$ and $d_{t}$ and between $\theta_{\mathrm{AOD}}$ and $d_{\mathrm{p}}$ are not exactly linear (i.e., the outlier in Fig. 8a). While similar AOD patterns yield similar climate responses, different AOD patterns do not guarantee different climate responses, which indicates we might explore too many options and the number of meaningfully independent DOFs might be smaller than what we find in this study. However, this is better than possibly ignoring important DOFs.
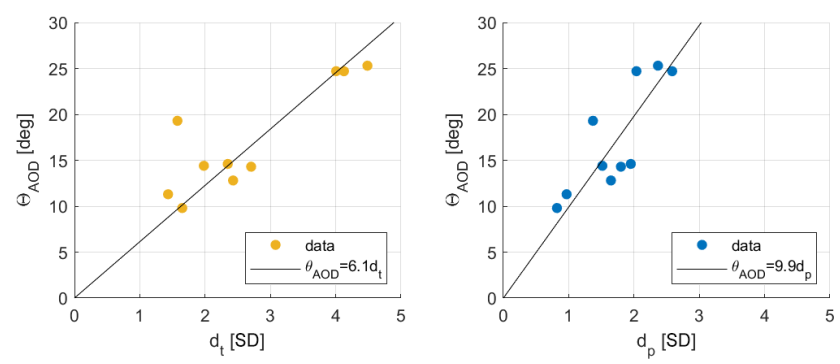

Figure 8. (a) Angle between AOD patterns, $\theta_{\mathrm{AOD}}$, and the distance between corresponding temperature responses, $d_{t}$, for each pair of strategies in Table 1; (b) angle between AOD patterns, $\theta_{\mathrm{AOD}}$, and the distance between corresponding precipitation responses, $d_{\mathrm{p}}$, for each pair of strategies in Table $1 . d_{t}$ and $d_{\mathrm{p}}$ are expressed in the number of SDs of 20-year averages of temperature and precipitation respectively. Orange dots represent the values of $\theta_{\mathrm{AOD}}$ and corresponding $d_{t}$ and blue dots represent the values of $\theta_{\mathrm{AOD}}$ and corresponding $d_{\mathrm{p}}$ of all pairwise comparisons between different strategies. The black lines represent the best-fit linear regression functions, constrained to pass through the origin: $\theta_{\mathrm{AOD}}=6.1 d_{t}$, and $\theta_{\mathrm{AOD}}=9.9 d_{\mathrm{p}}$ with the coefficient of determination, $R_{t}^{2}=0.62$ and $R_{\mathrm{p}}^{2}=0.65$, respectively. The error in estimating each point (calculated from across-ensemble variability) is small (less than $0.2^{\circ}$ in AOD angle, and less than $0.1 \mathrm{SD}$ in both temperature distance and precipitation distance) compared to the fitting error, indicating that a linear approximation to the relationship is only an approximation. Points in the upper right (most dissimilar AOD and dissimilar surface climate) are the pairwise comparisons between the equatorial injection strategy and the other strategies. In panel (a), the outlier at approximately $(1.6,19)$, which is the comparison between iSpring and iAutumn, shows that the relationship between $\theta_{\mathrm{AOD}}$ and $d_{t}$ is not exactly linear; similar AOD patterns yield similar climate responses but different AOD patterns do not guarantee different climate responses.

Data used here are from SAI designs that were considered in previous studies. Although they are not designed to span either the overall AOD design space or the surface climate design space, these available simulations do provide a useful set of data for analyzing the relationship between how similar or dissimilar the AOD patterns are and how similar or dissimilar the surface climate responses are.

\section{Detectability at different levels of cooling}

To evaluate how different the surface climate responses are, we first perform Welch's $t$ test on the five injection strategies, using a single ensemble member of each injection strategy. Welch's $t$-test assumes that sampled data are independent; we remove the effect of serial autocorrelation from the temperature and precipitation data by estimating the effective sample size assuming both temperature and precipitation follow a first-order autoregressive (AR(1)) process (Wilks, 2019). The $t$-test results for comparing differences in surface air temperature between GLENS and iSpring and between 


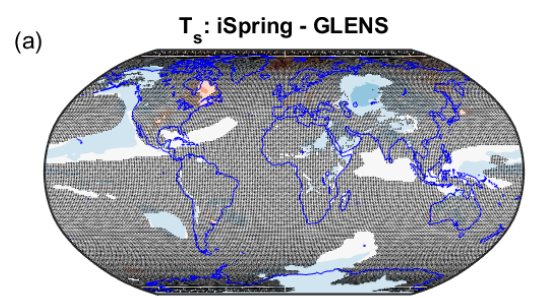

(c)

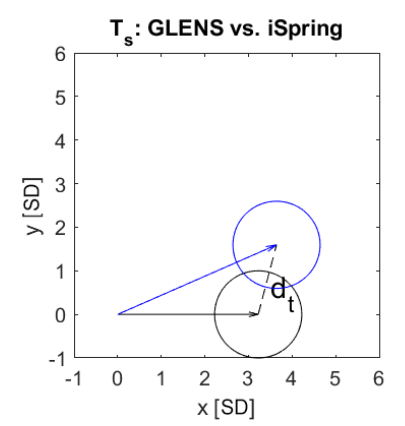

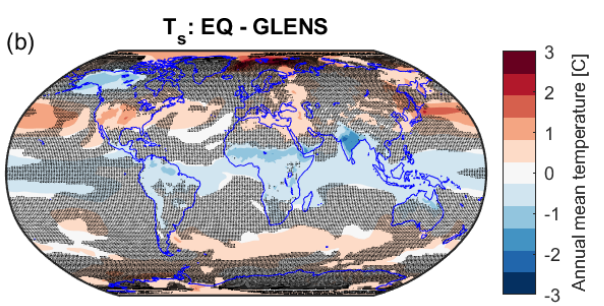

(d)

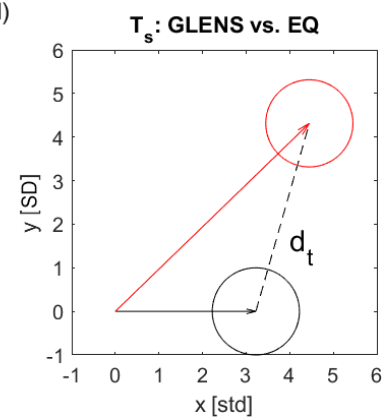

Figure 9. Panels (a, c) show the comparison between GLENS and iSpring; (b, d) show the comparison between GLENS and EQ. Panels (a) and (b) show the difference in temperature responses between GLENS and iSpring and between GLENS and EQ, respectively; shaded areas are where no statistically significant difference is observed, based on a $t$ test with a confidence level of $95 \%$. Panels (c) and (d) are detectability plots that geometrically show the ability of detecting differences in the temperature responses between GLENS (black) and iSpring (blue) and between GLENS and EQ (red), respectively. The temperature responses are expressed in the number of standard deviations (SDs) of 20-year averages of temperature. Both the $x$ and $y$ axes are distances in the number of standard deviations. The length of each vector represents the area-weighted $L^{2}$ norm of surface air temperature response, and the circle represents temperature variability in all possible directions, with a radius of $1 \mathrm{SD}$ due to the normalization. The dashed line in panels (c) and (d) measures the temperature distance, $d_{t}$, between GLENS and iSpring and between GLENS and EQ, respectively. GLENS and EQ have a larger distance in the temperature response, which indicates the difference between GLENS and EQ is more detectable at the same level of cooling.

GLENS and EQ are shown in Fig. 9a and b; the $t$-test results for precipitation comparison are shown in Fig. 10a and b. At a $4{ }^{\circ} \mathrm{C}$ cooling and a confidence level of $95 \%$, temperature and precipitation responses from GLENS and iSpring are statistically significantly different from each other in $17 \%$ and $7 \%$ of Earth's area, respectively, as opposed to the comparison between GLENS and EQ, in which $37 \%$ and $23 \%$ of area on the Earth show statistically significant difference in temperature and precipitation.

Here, we define that two strategies are considered to be detectably different if the difference in temperature or precipitation responses between them are detectable at a $95 \%$ confidence level over a 20-year period on more than $5 \%$ of the Earth's area. With the temperature and precipitation normalized by the standard deviation of 20 -year means, temperature or precipitation responses at any grid point will be detectably different if the difference between the normalized data is more than 2 SD (standard deviations). To obtain a global aggregate metric, we note that roughly $5 \%$ of the Earth's surface area has a temperature difference more than double the overall temperature distance $d_{t}$ considered earlier and $5 \%$ of the Earth's surface area has a precipitation difference more than double the precipitation distance $d_{\mathrm{p}}$. (For example, between GLENS and iSpring, only $5.2 \%$ of the Earth's area has a difference in regional temperature responses that is more than twice the value of $d_{t}$, and only $4.7 \%$ of the Earth's area has a difference in regional precipitation responses that is more than twice the value of $d_{\mathrm{p}}$.) Thus, when the temperature distance $d_{t}$ between two injection strategies is 1 standard deviation, then roughly $5 \%$ of the Earth's surface area will have detectably different temperature responses at a $95 \%$ confidence interval. Similarly, when the precipitation distance $d_{\mathrm{p}}$ between two injection strategies is 1 standard deviation, then roughly $5 \%$ of the Earth's surface area will have detectably different precipitation responses at a $95 \%$ confidence interval. Thus, we use 1 standard deviation of the overall rms normalized temperature distance or precipitation distance as the threshold for determining whether two strategies result in detectably different temperature or precipitation responses.

We compare the difference in temperature and precipitation responses between GLENS and iSpring and between GLENS and EQ, and show how the difference changes with levels of cooling using detectability plots, as shown in Figs. 9c, d and 10c, d. Figures 9c and 10c show the detectability of difference in temperature and precipitation between GLENS and iSpring at a cooling level of $4{ }^{\circ} \mathrm{C}$. Figures $9 \mathrm{~d}$ and 10d show the comparison between GLENS and EQ at the same cooling level. In each plot, the length of the vector is equal to the area-weighted $L^{2}$ norm of the corresponding temperature or precipitation vector, and the 


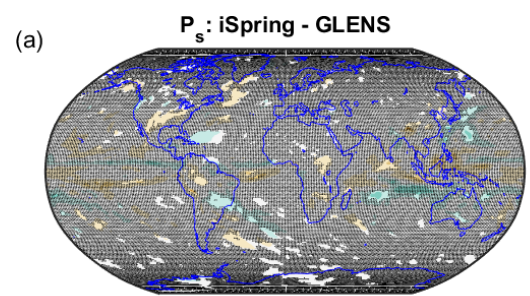

(c)

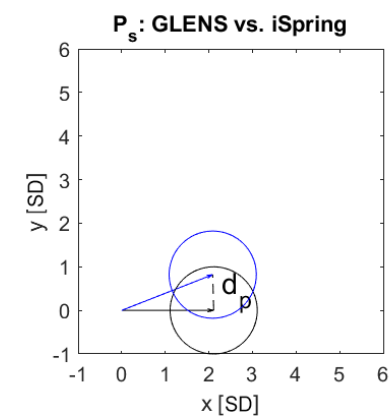

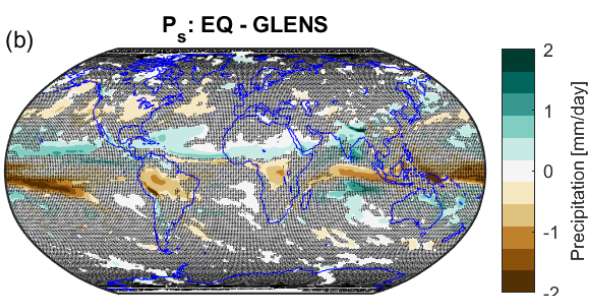

(d)

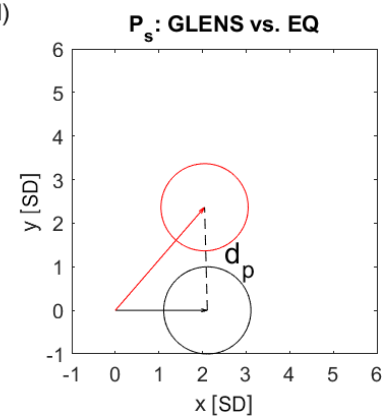

Figure 10. Panels (a, c) show the comparison between GLENS and iSpring; (b, d) show the comparison between GLENS and EQ. Panels (a) and (b) show the difference in precipitation responses between GLENS and iSpring and between GLENS and EQ, respectively; shaded areas are where no statistically significant difference is observed, based on a $t$ test with a confidence level of $95 \%$. Panels (c) and (d) are detectability plots that geometrically show the ability of detecting differences in the precipitation responses between GLENS (black) and iSpring (blue) and between GLENS and EQ (red), respectively. The precipitation responses are expressed in the number of SDs of 20-year averages of precipitation. Both the $x$ and $y$ axes are distances in the number of standard deviations. The length of each vector represents the area-weighted $L^{2}$ norm of precipitation response, and the circle represents precipitation variability in all possible directions, with a radius of $1 \mathrm{SD}$ due to the normalization. The dashed line in panels (c) and (d) measures the precipitation distance, $d_{\mathrm{p}}$, between GLENS and iSpring and between GLENS and EQ, respectively. Similar to temperature response, the difference in precipitation between GLENS and EQ is more detectable than that between GLENS and iSpring at the same level of cooling.

distance between the two vectors is the corresponding temperature distance or precipitation distance. The circle around the tip of each vector represents the temperature or precipitation variability on a 20 -year timescale, whose radius is equal to one due to the normalization by the standard deviation of temperature or precipitation variability. In Fig. 9c, the two temperature variability circles partially overlap, while in Fig. 9d, the two circles are separated from each other. The more overlapped these two circles are, the less area has detectably different temperature responses. When the overlapped area is sufficiently large, it indicates that the difference in temperature responses is small enough such that it is hard to tell whether the difference could be purely due to natural variability. These implications from the observation of temperature responses also apply to precipitation.

From the detectability plots that compare these different SAI strategies, it is clear that the detectability of different injection strategies depends on both the level of cooling and the choice of climate variables. With the underlying assumption of linearity for surface climate responses, we estimate the difference in temperature and precipitation responses between GLENS and EQ at reduced levels of cooling (Fig. 11). For the same pair of strategies, as we reduce the amount of cooling, the temperature distance and the precipitation distance between these two strategies decrease. At $1.8^{\circ} \mathrm{C}$ cooling, the resulting temperature responses of these two strategies are $2 \mathrm{SDs}$ of temperature variability away from each other (Fig. 11b); at the same level of cooling, the resulting precipitation responses are $1 \mathrm{SD}$ apart (Fig. 11e). At $0.9^{\circ} \mathrm{C}$ cooling, the resulting temperature responses are exactly $1 \mathrm{SD}$ apart (Fig. 11c), and the precipitation responses are $0.5 \mathrm{SD}$ apart (Fig. 11f). For any cooling level lower than $0.9^{\circ} \mathrm{C}$, temperature responses of GLENS and EQ will not be detectably different by our metric; that is to say, less than $5 \%$ of area on the Earth is expected to have detectably different temperature responses at a $95 \%$ confidence level over a 20 -year period. On the other hand, to have detectably different precipitation responses between GLENS and EQ, the cooling level needs to be higher than $1.8^{\circ} \mathrm{C}$. The cooling levels of 0.9 and $1.8^{\circ} \mathrm{C}$ are defined as the cut-off cooling levels for detectable difference in temperature and precipitation, respectively, between GLENS and EQ. Note that for sufficiently small amounts of cooling, the resulting climate from these strategies will also be undetectably different from the climate with neither increased greenhouse gases nor SAI; from Fig. 7, they will be detectably different from the climate with increased GHGs except at very small levels of cooling.

As shown in Fig. 11, the cut-off level of cooling $\Delta T_{t}$ is inversely proportional to $d_{t}$ and the cut-off level of cooling $\Delta T_{\mathrm{p}}$ is inversely proportional to $d_{\mathrm{p}}$ : 

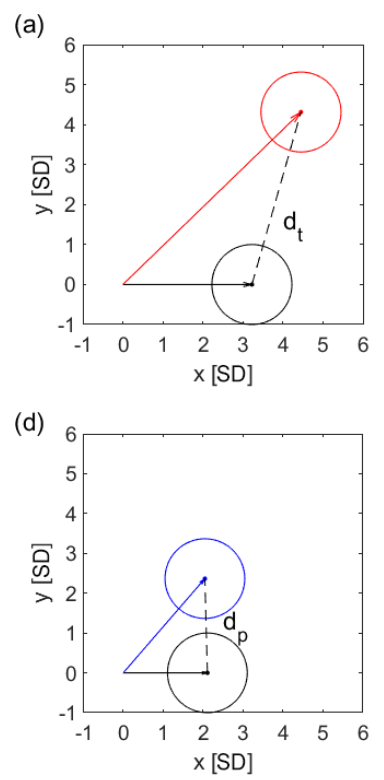

(b)

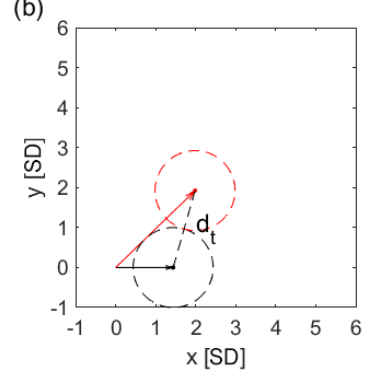

(e)

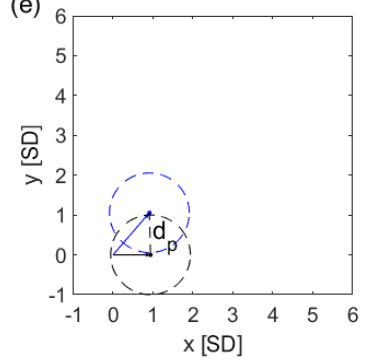

(c)

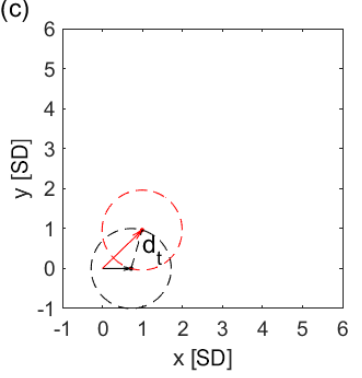

(f)

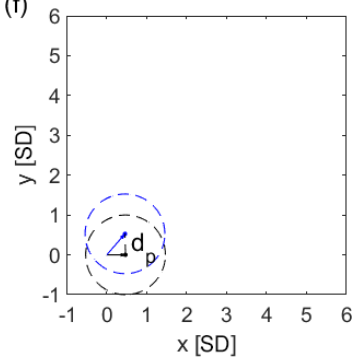

Figure 11. Panels (a)-(c) are detectability plots for the difference in temperature responses between GLENS (black) and EQ (red) at three different levels of cooling: (a) $4{ }^{\circ} \mathrm{C}$, (b) $1.8^{\circ} \mathrm{C}$, and (c) $0.9^{\circ} \mathrm{C}$. Panels (d)-(f) are detectability plots for the difference in precipitation responses between GLENS (black) and EQ (red) at those three levels of cooling. Dots represent the estimated mean temperature or precipitation responses for the corresponding levels of cooling. Temperature and precipitation responses are expressed in the number of SDs of 20-year averages of temperature and precipitation respectively. In each plot, both the $x$ and $y$ axes are distances in the number of standard deviations. As the cooling level decreases, less area on the Earth has detectably different climate responses, and the ability to detect the difference between GLENS and EQ decreases.

$$
\begin{aligned}
\Delta T_{t} & =\frac{4}{d_{t}} \\
\Delta T_{\mathrm{p}} & =\frac{4}{d_{\mathrm{p}}} .
\end{aligned}
$$

By substituting Eq. (10) into Eq. (8) and substituting Eq. (11) into Eq. (9), we obtain two functions that can be used to estimate a threshold value of AOD angle, $\theta_{\mathrm{a}}$, which is used to assess the detectability of different injection choices at different levels of cooling:

$\theta_{\mathrm{a}}^{t}=24 / \Delta T_{t}$

$\theta_{\mathrm{a}}^{\mathrm{p}}=40 / \Delta T_{\mathrm{p}}$.

Thus, given a particular level of cooling, we can calculate if two injection strategies are expected to result in detectably different temperature or precipitation responses by comparing their AOD patterns. If the angle between the patterns of AOD is smaller than $\theta_{\mathrm{a}}^{t}$ or $\theta_{\mathrm{a}}^{\mathrm{p}}$, these two strategies can be expected to not result in detectably different temperature or precipitation responses. However, if the angle between the patterns of AOD is larger than $\theta_{\mathrm{a}}^{t}$ or $\theta_{\mathrm{a}}^{\mathrm{p}}$, these two strategies can be expected to be meaningfully independent in terms of temperature responses or precipitation responses. In Fig. 12, we compare the cut-off AOD angles predicted by Eqs. (12) and (13). As shown in Fig. 12, the threshold values of AOD angle predicted using temperature responses

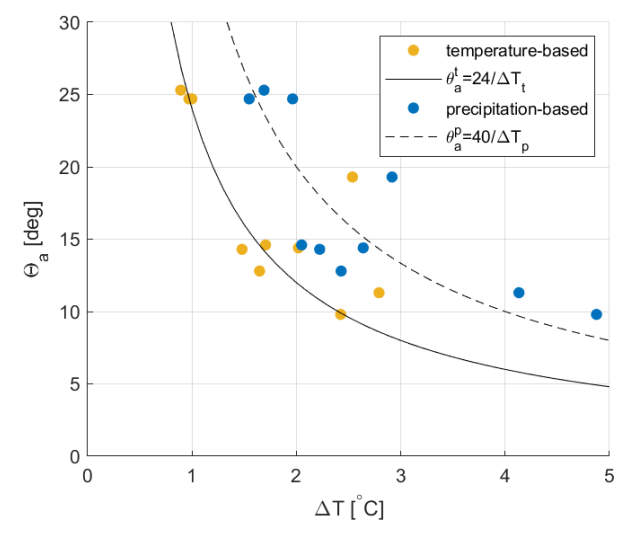

Figure 12. The cut-off AOD angle $\theta_{\mathrm{a}}$ at different levels of cooling $\Delta T$ estimated using temperature responses and precipitation responses.

are always lower than those predicted using precipitation responses.

\section{Estimating the number of DOFs}

In the previous sections, we estimate the relationship between the number of DOFs included and the maximum error in approximating AOD, and the relationship between the AOD angle and the level of cooling at which the resulting 
Table 2. The minimum number of DOFs, $n$, of the SAI design space for four targeted levels of cooling. At each level of cooling, $\theta_{\mathrm{a}}^{t}$ is the maximum angle that can be formed between two AOD patterns that yield undetectably different temperature responses. $\theta^{*}(n)$ is the maximum angle that can be formed between any AOD pattern and the design space of $n$ DOFs and must be smaller than $\theta_{\mathrm{a}}^{t}$.

\begin{tabular}{lcrl}
\hline $\begin{array}{l}\text { Targeted } \\
\text { level of } \\
\text { cooling } \\
{\left[{ }^{\circ} \mathrm{C}\right]}\end{array}$ & $\begin{array}{c}\text { Cut-off } \\
\text { angle } \\
\theta_{\mathrm{a}}^{t}\end{array}$ & $\begin{array}{c}\text { Minimum } \\
\text { number of } \\
\text { DOFs, } n\end{array}$ & $\theta^{*}(n)$ \\
\hline 0.5 & $48^{\circ}$ & 2 & $38^{\circ}$ \\
1 & $24^{\circ}$ & 6 & $18^{\circ}$ \\
1.5 & $16^{\circ}$ & 8 & $15^{\circ}$ \\
2 & $12^{\circ}$ & 12 & $11^{\circ}$ \\
\hline
\end{tabular}

temperature or precipitation responses could be expected to be detectably different. In this section, we combine these two to estimate how many meaningfully independent DOFs there are as a function of the levels of cooling.

As changes in temperature are more detectable than those in precipitation, the extent to which two AOD patterns are sufficiently similar, and thus the number of DOFs in the SAI design space, is determined by the temperature response. Using Eq. (12), we calculate the cut-off AOD angle $\theta_{\mathrm{a}}^{t}$ (listed in Table 2) for cooling levels of $0.5,1,1.5$, and $2{ }^{\circ} \mathrm{C}$. It is expected that two SAI strategies, with AOD differing by any angle smaller than $\theta_{\mathrm{a}}^{t}$, will not result in detectably different temperature or precipitation responses. Figure 13 shows the four cut-off AOD angles and the corresponding minimum numbers of DOFs required for $\theta^{*}(n)$ not exceeding the cutoff value, $\theta_{\mathrm{a}}^{t}$ (also listed in Table 2).

$\theta^{*}(n) \leq \theta_{\mathrm{a}}^{t}(\Delta T)$

Any set of injection choices that has a $\theta_{\max }$ smaller than the cut-off angle $\theta_{\mathrm{a}}^{t}(\Delta T)$ will form a design space that captures all detectably different climate responses. That is, for any possible injection strategy not included in the design space, you can find an injection strategy in the design space such that the angle between their AOD patterns is smaller than $\theta_{\mathrm{a}}^{t}$ and the difference in the corresponding climate responses is sufficiently small such that they are not meaningfully different.

As shown in Table 2, as the targeted level of cooling increases, the cut-off value of $\theta_{\mathrm{a}}^{t}$ decreases and the minimum number of DOFs increases. For a targeted cooling level of $1{ }^{\circ} \mathrm{C}$, we likely need 6 DOFs. For any possible AOD pattern, the angle between it and the AOD pattern approximated by a design space of 6 DOFs is likely to be smaller than $24^{\circ}$, and the resulting difference in climate response will be largely undetectable. For a targeted cooling level of $1.5^{\circ} \mathrm{C}$, we likely need 8 DOFs. This finding significantly reduces the dimension of the design space needed for evaluating the possible

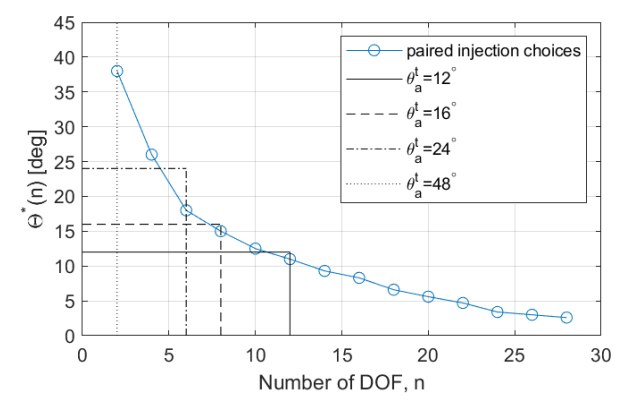

Figure 13. The minimum number of DOFs corresponding to the worst-case error in approximating $\operatorname{AOD}, \theta_{\mathrm{a}}^{t}$.

climate impacts of different SAI strategies and associated trade-offs.

For a cooling level of $1{ }^{\circ} \mathrm{C}$, the best set of six among the set of 29 sample injection choices includes (i) spring injections at $60^{\circ} \mathrm{N} / 60^{\circ} \mathrm{S}$, (ii) annual injections at $30^{\circ} \mathrm{N} / 30^{\circ} \mathrm{S}$, and (iii) winter and summer injections at the Equator. Figure 14 shows the AOD spatiotemporal patterns of the six injections in the best set. A set of six that instead includes annually constant injection at $30,15^{\circ} \mathrm{N}, 15$, and $30^{\circ} \mathrm{S}$ (the four cases considered in MacMartin et al., 2017; Kravitz et al., 2017; Tilmes et al., 2018a) as well as spring injection at $60^{\circ} \mathrm{N}$ (as in Lee et al., 2021) and $60^{\circ} \mathrm{S}$ is only slightly worse than this optimal set, within a range of $0.1^{\circ}$, still sufficient to span the design space for $1^{\circ} \mathrm{C}$ cooling.

For a cooling level of $1.5^{\circ} \mathrm{C}$, the best set of eight is similar to the best set of six but with equatorial injections at the other two seasons instead and the addition of summer injections at $15^{\circ} \mathrm{N}$ and $15^{\circ} \mathrm{S}$. Note that in the optimization earlier, we constrained our search to hemispherically symmetric pairs of injection choices. Including only annually constant injection at the Equator rather than two seasons yields a set of seven injection choices that performs almost as well as the optimal set of eight and is still sufficient for $1.5^{\circ} \mathrm{C}$ cooling.

\section{Analysis of injections at different altitudes}

The SAI simulations analyzed in the previous sections are all high-altitude injections (6-7 km above the tropopause). Tilmes et al. (2017) also conducted low-altitude ( $5 \mathrm{~km}$ lower) simulations at $50^{\circ} \mathrm{N}, 30^{\circ} \mathrm{N}, 15^{\circ} \mathrm{N}, 0^{\circ}, 15^{\circ} \mathrm{S}, 30^{\circ} \mathrm{S}$, and $50^{\circ} \mathrm{S}$ with an annual injection rate of $6 \mathrm{Tg}^{-1}$, all simulated in CESM1(WACCM). The AOD patterns of low-altitude and high-altitude injections are shown in Fig. 15. For each injection case, the spatiotemporal AOD responses are weighted by TOA incoming solar energy. The angle of the AOD pattern of each high-altitude injection with respect to the set of all lowaltitude injections is listed in Table 3; these high-altitude injections are all within a small angle with respect to the set of low-altitude injections. For a level of cooling under $2{ }^{\circ} \mathrm{C}$, the difference of AOD responses due to injecting at these different altitudes is small compared to the differences achievable 
(a)

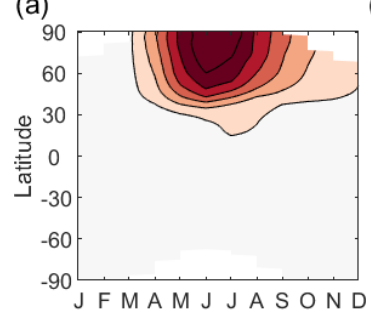

(d)

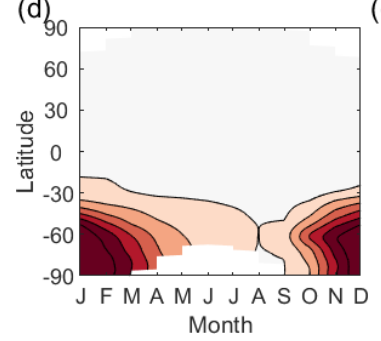

(b)

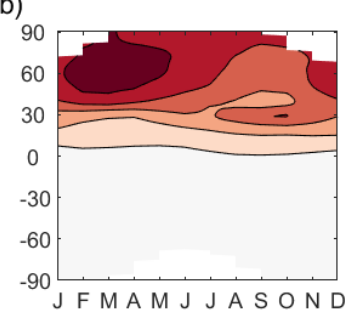

(c)

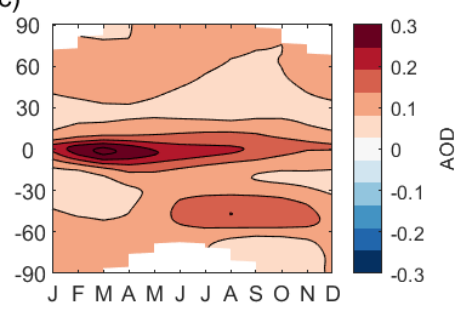

(e)

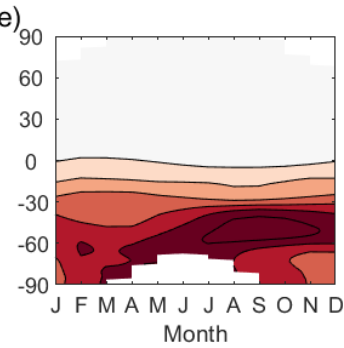

Figure 14. AOD patterns from the best set of six injections: (a) spring injection at $60^{\circ} \mathrm{N}$, (b) annual injection at $30^{\circ} \mathrm{N}$, (c) winter injection at $0^{\circ}$, (d) spring injection at $60^{\circ} \mathrm{S}$, (e) annual injection at $30^{\circ} \mathrm{S}$, and (f) summer injection at $0^{\circ}$.

Table 3. Angle between the AOD vector of each high-altitude injection and the set of all low-altitude injections.

\begin{tabular}{lccccccc}
\hline $\begin{array}{l}\text { Injection } \\
\text { latitude }\end{array}$ & $50^{\circ} \mathrm{N}$ & $30^{\circ} \mathrm{N}$ & $15^{\circ} \mathrm{N}$ & $0^{\circ}$ & $15^{\circ} \mathrm{S}$ & $30^{\circ} \mathrm{S}$ & $50^{\circ} \mathrm{S}$ \\
\hline$\theta_{\mathrm{AOD}}$ & $5.3^{\circ}$ & $11.6^{\circ}$ & $6.2^{\circ}$ & $7.0^{\circ}$ & $4.5^{\circ}$ & $6.3^{\circ}$ & $4.9^{\circ}$ \\
\hline
\end{tabular}

through injecting at different latitudes and seasons. If a much higher level of cooling is desired, injecting at different altitudes may result in meaningfully different surface climates and injection choices of different altitudes may need to be considered when choosing the design space and evaluating trade-offs. Injection at or below the tropopause, while inefficient, would likely result in more significant differences in AOD patterns (Bernstein et al., 2013). Thus, injection at or below the tropopause could add further degrees of freedom at the expense of a significant loss of efficiency.

\section{Conclusions}

Previous studies have shown that different choices of stratospheric aerosol injection latitudes and seasons lead to different surface climate responses. Choosing where and when to inject aerosols to the stratosphere to meet different climate goals can be considered a design problem. Previous studies have concluded that there are at least 3 DOFs; that is, at least three independent climate goals can be simultaneously met. These three - basically the global mean aerosol burden, the interhemispheric difference, and the Equator-to-pole difference - were motivated by physical intuition regarding stratospheric transport, which will ultimately constrain how many independent DOFs are achievable through different injection choices. A key observation is that the number of DOFs effectively depends on the amount of global cooling provided by SAI, because for a small amount of cooling, the difference in the climate response for different strategies may not be detectable. As the amount of cooling increases, the number of meaningfully independent DOFs increases. For a cooling level of $1-1.5^{\circ} \mathrm{C}$, there are likely between 6 and 8 meaningfully independent DOFs. If only precipitation changes mattered, and not temperature changes, then there would be fewer meaningfully independent DOFs.

The choice of 20-year average, as well as the choice of $95 \%$ confidence threshold over $5 \%$ of the Earth's area, affects the number of DOFs that are "meaningfully different". Considering the responses over a longer period of time might introduce additional DOFs. To date, current climate models have relatively high confidence in predicting temperature responses but have lower confidence in predicting circulation-related responses and much lower confidence in predicting regional-scale circulation-related extreme events (Shepherd, 2014). The number of DOFs is primarily driven by the differences in temperature responses. Precipitation and circulation-related extreme events are typically harder to detect and are not likely to introduce additional DOFs; that is, as the amount of cooling is gradually increased (or as the time horizon is increased), two distinct strategies are likely to become detectably different in their temperature response earlier than for precipitation changes or changes in extremes.

When evaluating the design space, we do not consider injections at different longitudes and additional altitudes beyond those evaluated in Sect. 3, nor do we consider adaptive injection strategies as explored by Aksamit et al. (2021). The longitude is not expected to matter due to rapid zonal mixing in the stratosphere. As the injection altitude approaches the 
(a)

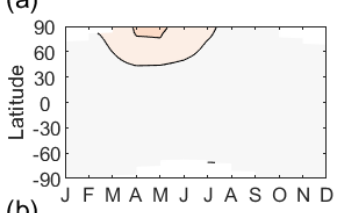

(b)

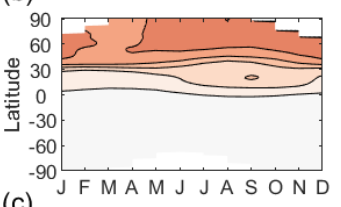

(c)

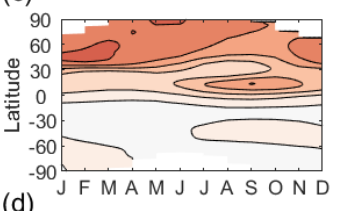

(d)

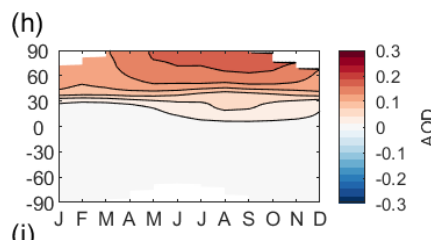

(i)

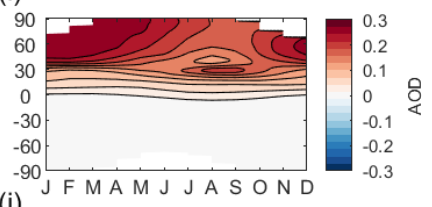

(j)

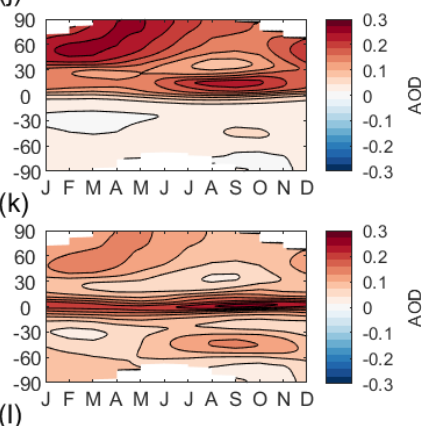

(e)
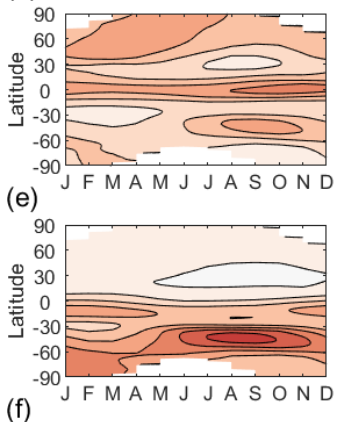

(f)

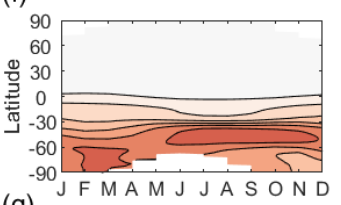

(g)

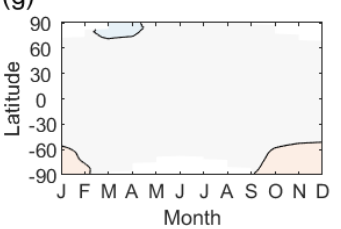

(I)
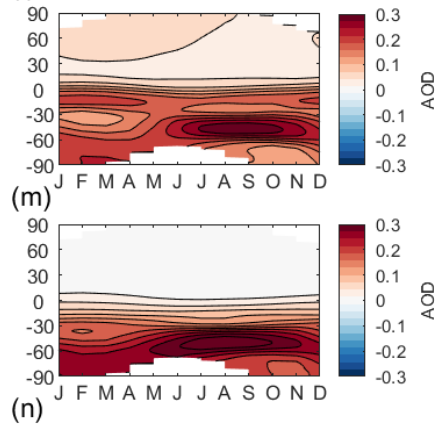

(n)

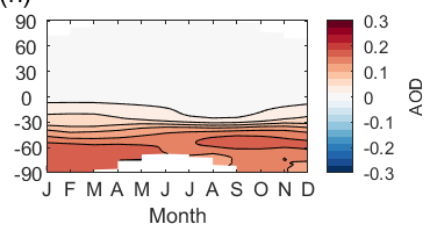

Figure 15. AOD patterns produced by low-altitude annually constant injection of $6 \mathrm{Tg} \mathrm{yr}^{-1}$ at (a) $50^{\circ} \mathrm{N}$, (b) $30^{\circ} \mathrm{N}$, (c) $15^{\circ} \mathrm{N}$, (d) $0^{\circ}$, (e) $15^{\circ} \mathrm{S}$, (f) $30^{\circ} \mathrm{S}$, and (g) $50^{\circ} \mathrm{S}$, and high-altitude annually constant injection of $6 \mathrm{Tg} \mathrm{yr}^{-1}$ at (h) $50^{\circ} \mathrm{N}$, (i) $30^{\circ} \mathrm{N},\left(\right.$ j) $15^{\circ} \mathrm{N}$, (k) $0^{\circ}$, (l) $15^{\circ} \mathrm{S}$, (m) $30^{\circ} \mathrm{S}$, and (n) $50^{\circ} \mathrm{S}$.

tropopause, the lifetime in the stratosphere decreases, leading to more spatially and temporally confined changes to AOD that would add further degrees of freedom at the expense of a significant loss of efficiency.

Our estimation of the number of DOFs provides useful guidance to bound the number of injection choices that need to be considered when evaluating the range of possible different SAI strategies and the trade-offs among them. If only a small amount of cooling is needed from implementing SAI, a small set of selected injection choices would be sufficient to capture the range of possible resulting climate responses

and evaluate how different those climate responses could be. As all possible injection choices form an extremely highdimensional design space, only considering the meaningfully independent injection choices significantly reduces the dimension of the design space.

The number of meaningfully independent DOFs determines the number of independent climate metrics that SAI can manage simultaneously. Thus, for a cooling level of 1$1.5^{\circ} \mathrm{C}$, for example, SAI can manage six to eight independent climate metrics at the same time. This expands the manageable number of climate metrics relative to what has been considered in previous studies, opening up new opportunities for exploring alternate designs that will have different distributions of impacts.

It is important to note that all of these results are obtained from a single climate model. Other climate models may produce different numerical results. Nonetheless, the number of independent DOFs needed to span the range of possible different stratospheric AOD patterns can be reasonably expected to remain consistent as the transport of aerosols are constrained by stratospheric circulation. We make several simplifying approximations in order to make analysis tractable, particularly to estimate the relationship between how similar or dissimilar two patterns of AOD are and how similar or dissimilar the corresponding surface climate responses are; future research could explore the impact of these approximations. First, we only consider changes in temperature and precipitation, and we only consider changes in annual mean rather than shifts in seasonality, which could matter at high latitudes in particular (Jiang et al., 2019). Second, we only consider whether the difference in climate response would be detectable over a 20 -year period. Third, the globally aggregated metric we use for determining whether two different climate responses are "detectable" is based on whether they are detectably different at a $95 \%$ confidence level over $5 \%$ of the surface area. However, changes that are less-confidently detected may still matter, and since social, agricultural, and other economic activities are strongly affected by regional climate changes, just because they only happen in a small percentage of the area, does not necessarily mean that they are not important - the details of where and what the differences are potentially matter.

A key outcome of this study is that further research should be conducted to explore alternate SAI designs that can manage more than three and up to eight independent climate metrics simultaneously, and to compare the resulting climate responses and associated trade-offs. Research into more than eight is less policy-relevant, simply because any hypothetical deployment scenario would not reach more than $1.5^{\circ} \mathrm{C}$ cooling for many decades. Greater cooling might be needed under a higher emission scenario, which would add further degrees of freedom. Ultimately, to evaluate the impacts of stratospheric aerosol geoengineering, regional surface climate and extreme weather events need to be considered, as social and economic activities are significantly 
affected by regional climate change. Alternate SAI designs may enable a better compensation of the impacts from climate change; alternate designs might also lead to the potential to create more novel climates that optimize some metrics at the expense of others - both of these possibilities are important to understand in order to inform not only future scientific research in SAI but also governance challenges.

Data availability. Data for the new simulations presented in this study (specifically, monthly AOD for spring injections at 60, $45^{\circ} \mathrm{N}, 45$, and $60^{\circ} \mathrm{S}$ and annually constant injections at 7.5, 22.5, and $37.5^{\circ} \mathrm{N}$ ) are available through the Cornell e-Commons Library at https://doi.org/10.7298/f1e4-sq40 (Zhang et al., 2021). Data for GLENS and equatorial simulations (from Tilmes et al., 2018a and Kravitz et al., 2019, respectively) are available at https://doi.org/10.5065/D6JH3JXX (Tilmes et al., 2018b), data for iSpring and iAutumn (from Visioni et al., 2020c) are available at https://doi.org/10.7298/c92j-2p46 (Visioni et al., 2020a), and data for PREC (from Lee et al., 2020a) are available at https://doi.org/10.7298/d2qm-1568 (Lee et al., 2020b).

Author contributions. YZ conducted all analyses and wrote the paper with editing by DGM, BK, and DV. YZ and DGM conceived the study with input from all authors, and DV assisted with conducting simulations.

Competing interests. At least one of the (co-)authors is a member of the editorial board of Earth System Dynamics. The peerreview process was guided by an independent editor, and the authors also have no other competing interests to declare.

Disclaimer. Publisher's note: Copernicus Publications remains neutral with regard to jurisdictional claims in published maps and institutional affiliations.

Special issue statement. This article is part of the special issue "Resolving uncertainties in solar geoengineering through multi-model and large-ensemble simulations (ACP/ESD interjournal SI)". It is not associated with a conference.

Acknowledgements. The authors would like to acknowledge high-performance computing support from Cheyenne (https://doi.org/10.5065/D6RX99HX) provided by NCAR's Computational and Information Systems Laboratory, sponsored by the National Science Foundation. Support for Yan Zhang and Douglas G. MacMartin was provided by the National Science Foundation through agreement nos. CBET-1818759 and CBET2038246. Support for Daniele Visioni was provided by the Atkinson Center for a Sustainable Future at Cornell University. Support for Ben Kravitz was provided in part by the National Science Foundation through agreement no. CBET-1931641, the Indiana University Environmental Resilience Institute, and the
Prepared for Environmental Change Grand Challenge initiative. The Pacific Northwest National Laboratory is operated for the US Department of Energy by Battelle Memorial Institute under contract no. DEAC05-76RL01830. The CESM project is supported primarily by the National Science Foundation.

Financial support. This research has been supported by the National Science Foundation (grant nos. CBET-1818759, CBET2038246, and CBET-1931641).

Review statement. This paper was edited by Roland Séférian and reviewed by two anonymous referees.

\section{References}

Aksamit, N. O., Kravitz, B., MacMartin, D. G., and Haller, G.: Harnessing Stratospheric Diffusion Barriers for Enhanced Climate Geoengineering, Atmos. Chem. Phys., 21, 8845-8861, https://doi.org/10.5194/acp-21-8845-2021, 2021.

Bala, G., Duffy, P. B., and Taylor, K. E.: Impact of geoengineering schemes on the global hydrological cycle, P. Natl. Acad. Sci. USA, 105, 7664-7669, https://doi.org/10.1073/pnas.0711648105, 2008.

Ban-Weiss, G. A. and Caldeira, K.: Geoengineering as an optimization problem, Environ. Res. Lett., 5, 034009, https://doi.org/10.1088/1748-9326/5/3/034009, 2010.

Bernstein, D. N., Neelin, J. D., Li, Q. B., and Chen, D.: Could aerosol emissions be used for regional heat wave mitigation?, Atmos. Chem. Phys., 13, 6373-6390, https://doi.org/10.5194/acp13-6373-2013, 2013.

Dai, Z., Weisenstein, D., and Keith, D. W.: Tailoring meridional and seasonal radiative forcing by sulfate aerosol solar geoengineering, Geophys. Res. Lett., 45, 1030-1039, https://doi.org/10.1002/2017GL076472, 2018.

Jiang, J., Cao, L., MacMartin, D. G., Simpson, I. R., Kravitz, B., Cheng, W., Visioni, D., Tilmes, S., Richter, J. H., and Mills, M. J.: Stratospheric Sulfate Aerosol Geoengineering Could Alter the High-Latitude Seasonal Cycle, Geophys. Res. Lett., 46, 1415314163, https://doi.org/10.1029/2019GL085758, 2019.

Kravitz, B., Robock, A., Boucher, O., Schmidt, H., Taylor, K. E., Stenchikov, G., and Schulz, M.: The Geoengineering Model Intercomparison Project (GeoMIP), Atmos. Sci. Lett., 12, 162167, https://doi.org/10.1002/asl.316, 2011.

Kravitz, B., Robock, A., Tilmes, S., Boucher, O., English, J. M., Irvine, P. J., Jones, A., Lawrence, M. G., MacCracken, M., Muri, H., Moore, J. C., Niemeier, U., Phipps, S. J., Sillmann, J., Storelvmo, T., Wang, H., and Watanabe, S.: The Geoengineering Model Intercomparison Project Phase 6 (GeoMIP6): simulation design and preliminary results, Geosci. Model Dev., 8, 33793392, https://doi.org/10.5194/gmd-8-3379-2015, 2015.

Kravitz, B., MacMartin, D. G., Wang, H., and Rasch, P. J.: Geoengineering as a Design Problem, Earth Syst. Dynam., 7, 469-497, https://doi.org/10.5194/esd-7-469-2016, 2016.

Kravitz, B., MacMartin, D. G., Mills, M. J., Richter, J. H., Tilmes, S., Lamarque, J.-F., Tribbia, J. J., and Vitt, F.: First simulations of designing stratospheric sulfate aerosol 
geoengineering to meet multiple simultaneous climate objectives, J. Geophys. Res.-Atmos., 122, 12616-12634, https://doi.org/10.1002/2017JD026874, 2017.

Kravitz, B., MacMartin, D. G., Tilmes, S., Richter, J. H., Mills, M. J., Cheng, W., Dagon, K., Glanville, A. S., Lamarque, J.F., Simpson, I. R., Tribbia, J., and Vitt, F.: Comparing surface and stratospheric impacts of geoengineering with different $\mathrm{SO}_{2}$ injection strategies, J. Geophys. Res.-Atmos., 124, 7900-7918, https://doi.org/10.1029/2019JD030329, 2019.

Lee, W., MacMartin, D., Visioni, D., and Kravitz, B.: Expanding the design space of stratospheric aerosol geoengineering to include precipitation-based objectives and explore trade-offs, Earth Syst. Dynam., 11, 1051-1072, https://doi.org/10.5194/esd-111051-2020, 2020a.

Lee, W., MacMartin, D., Visioni, D., and Kravitz, B.: Data from: Expanding the design space of stratospheric aerosol geoengineering to include precipitation-based objectives and explore trade-offs, Cornell University eCommons Repository [data set], https://doi.org/10.7298/d2qm-1568, 2020b.

Lee, W., MacMartin, D., Visioni, D., and Kravitz, B.: HighLatitude stratospheric aerosol geoengineering can be more effective if injection is limited to spring, Geophys. Res. Lett., 48, e2021GL092696, https://doi.org/10.1029/2021GL092696, 2021.

MacMartin, D. G. and Kravitz, B.: The engineering of climate engineering, Annu. Rev. Contr. Robot. Autonom. Syst., 2, 445-467, https://doi.org/10.1146/annurev-control-053018-023725, 2019.

MacMartin, D. G., Kravitz, B., Tilmes, S., Richter, J. H., Mills, M. J., Lamarque, J.-F., Tribbia, J. J., and Vitt, F.: The climate response to stratospheric aerosol geoengineering can be tailored using multiple injection locations, J. Geophys. Res.-Atmos., 122, 12574-12590, https://doi.org/10.1002/2017JD026868, 2017.

Mills, M., Richter, J. H., Tilmes, S., Kravitz, B., MacMartin, D. G., Glanville, A. A., Tribbia, J. J., Lamarque, J.-F., Vitt, F., Schmidt, A., Gettelman, A., Hannay, C., Bacmeister, J. T., and Kinnison, D. E.: Radiative and chemical response to interactive stratospheric aerosols in fully coupled CESM1(WACCM), J. Geophys. Res.-Atmos., 122, 1306113078, https://doi.org/10.1002/2017JD027006, 2017.

Rasch, P. J., Crutzen, P. J., and Coleman, D. B.: Exploring the geoengineering of climate using stratospheric sulfate aerosols: The role of particle size, Geophys. Res. Lett., 35, L02809, https://doi.org/10.1029/2007GL032179, 2008.

Ricke, K. L., Granger Morgan, M., and Allen, M. R.: Regional climate response to solar-radiation management, Nat. Geosci., 3, 537-541, https://doi.org/10.1038/NGEO915, 2010.

Robock, A., Oman, L., and Stenchikov, G.: Regional climate responses to geoengineering with tropical and Arctic $\mathrm{SO}_{2}$ injections, J. Geophys. Res.-Atmos., 113, D16101, https://doi.org/10.1029/2008JD010050, 2008.

Shepherd, T. G.: Atmospheric circulation as a source of uncertainty in climate change projections, Nat. Geosci., 7, 703-708, https://doi.org/10.1038/ngeo2253, 2014.
Tilmes, S., Fasullo, J., Lamarque, J.-F., Marsh, D. R., Mills, M., Alterskjær, K., Muri, H., Kristjánsson, J. E., Boucher, O., Schulz, M., Cole, J. N. S., Curry, C. L., Jones, A., Haywood, J., Irvine, P. J., Ji, D., Moore, J. C., Karam, D. B., Kravitz, B., Rasch, P. J., Singh, B., Yoon, J.-H., Niemeier, U., Schmidt, H., Robock, A., Yang, S., and Watanabe, S.: The hydrological impact of geoengineering in the Geoengineering Model Intercomparison Project (GeoMIP), J. Geophys. Res.-Atmos., 118, 11036-11058, https://doi.org/10.1002/jgrd.50868, 2013.

Tilmes, S., Richter, J. H., Mills, M. J., Kravitz, B., MacMartin, D. G., Vitt, F., Tribbia, J. J., and Lamarque, J.-F.: Sensitivity of aerosol distribution and climate response to stratospheric $\mathrm{SO}_{2}$ injection locations, J. Geophys. Res.-Atmos., 122, 12591-12615, https://doi.org/10.1002/2017JD026888, 2017.

Tilmes, S., Richter, J. H., Kravitz, B., MacMartin, D. G., Mills, M. J., Simpson, I., Glanville, A. S., Fasullo, J. T., Phillips, A. S., Lamarque, J.-F., Tribbia, J., Edwards, J., Mickelson, S., and Gosh, S.: CESM1(WACCM) stratospheric aerosol geoengineering large ensemble (GLENS) project, B. Am. Meteorol. Soc., 99, 2361-2371, https://doi.org/10.1175/BAMS-D-170267.1, 2018a.

Tilmes, S., Richter, J. H., Kravitz, B., MacMartin, D. G., Mills, M. J., Simpson, I., Glanville, A. S., Fasullo, J. T., Phillips, A. S., Lamarque, J.-F., Tribbia, J., Edwards, J., Mickelson, S., and Gosh, S.: CESM1(WACCM) stratospheric aerosol geoengineering large ensemble (GLENS) project, National Center for Atmospheric Research (NCAR) [data set], https://doi.org/10.5065/D6JH3JXX, 2018b.

Visioni, D., MacMartin, D. G., Kravitz, B., Tilmes, S., Mills, M. J., Richter, J. H., and Boudreau, M. P.: Seasonal Injection Strategies for Stratospheric Aerosol Geoengineering, Geophys. Res. Lett., 46, 7790-7799, https://doi.org/10.1029/2019GL083680, 2019.

Visioni, D., MacMartin, D., Kravitz, B., Richter, Y., Tilmes, S., and Mills, M.: Data from: Seasonally Modulated Stratospheric Aerosol Geoengineering Alters the Climate Outcomes, Cornell University eCommons Repository [data set], https://doi.org/10.1029/2020GL088337, 2020a.

Visioni, D., MacMartin, D. G., Kravitz, B., Lee, W., Simpson, I. R., and Richter, J. H.: Reduced Poleward Transport Due to Stratospheric Heating Under Stratospheric Aerosols Geoengineering, Geophys. Res. Lett., 47, e2020GL089470, https://doi.org/10.1029/2020GL089470, 2020b.

Visioni, D., MacMartin, D. G., Kravitz, B., Richter, J. H., Tilmes, S., and Mills, M. J.: Seasonally Modulated Stratospheric Aerosol Geoengineering Alters the Climate Outcomes, Geophys. Res. Lett., 47, e2020GL088337, https://doi.org/10.1029/2020GL088337, 2020c.

Wilks, D. S.: Statistical methods in the atmospheric sciences, Elsevier, ISBN 9780128165270, 2019.

Zhang, Y., MacMartin, D., Visioni, D., and Kravitz, B.: Data from: How large is the design space for stratospheric aerosol geoengineering?, Cornell University eCommons Repository [data set], https://doi.org/10.7298/f1e4-sq40, 2021. 